\title{
As-Run Thermal Analysis for the CSM-10584 Experiment
}

Stacey M Wilson

October 2020

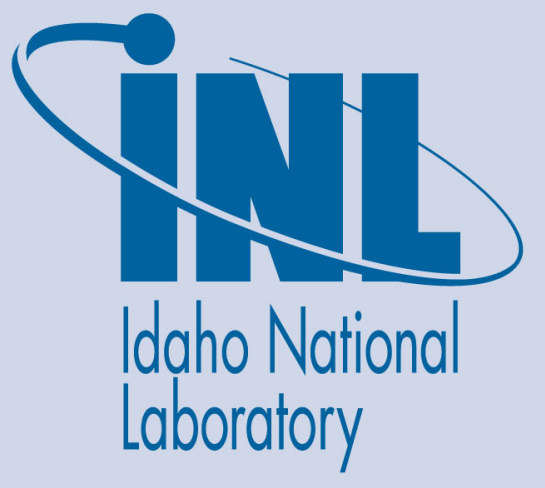

The INL is a U.S. Department of Energy National Laboratory operated by Battelle Energy Alliance 


\title{
As-Run Thermal Analysis for the CSM-10584 Experiment
}

\author{
Stacey M Wilson
}

October 2020

\begin{abstract}
Idaho National Laboratory Idaho Falls, Idaho 83415
\end{abstract}

http://www.inl.gov

Prepared for the

U.S. Department of Energy

Under DOE Idaho Operations Office

Contract DE-AC07-05ID14517 


\begin{tabular}{|c|c|c|}
\hline 1. Effective Date & $10 / 20 / 20$ & \multirow[t]{8}{*}{ Professional Engineer's Stamp } \\
\hline $\begin{array}{l}\text { 2. Does this ECAR involve a } \\
\text { Safety SSC? }\end{array}$ & No & \\
\hline $\begin{array}{l}\text { 3. Safety SSC Determination } \\
\text { Document ID }\end{array}$ & $\mathrm{N} / \mathrm{A}$ & \\
\hline 4. SSC ID & $\mathrm{N} / \mathrm{A}$ & \\
\hline 5. Project No. & N/A & \\
\hline 6. Engineering Job (EJ) No. & 2315 & \\
\hline 7. Building & TRA-670 & \\
\hline 8. Site Area & ATR Complex & \\
\hline
\end{tabular}

9. Objective / Purpose

The purpose of this document is to present the as-run specimen temperatures for the CSM-10584 experiment irradiated in position B-5 of the Advanced Test Reactor (ATR) for Cycles 164A and 164B.

10. If revision, please state the reason and list sections and/or page being affected.

\section{$\mathrm{N} / \mathrm{A}$}

11. Conclusion / Recommendations

The specimen temperatures at nominal power and nominal gas gap are between 263 to $392^{\circ} \mathrm{C}$ for Cycle $164 \mathrm{~A}$ and 266 to $387^{\circ} \mathrm{C}$ for Cycle 164B. The specimen temperatures at nominal power and considering capsule hot gas gaps are between 237 to $383^{\circ} \mathrm{C}$ for Cycle $164 \mathrm{~A}$ and 249 to $357^{\circ} \mathrm{C}$ for Cycle 164B. Detailed nominal power temperatures are in Appendix E.

The maximum temperature at various power level for each cycle at nominal gas gaps and hot gas gaps was calculated and graphed in Appendix E. The data was fit with the following $2^{\text {nd }}$ order polynomial equations used to calculate $y$, the maximum specimen temperatures $\left({ }^{\circ} \mathrm{C}\right)$, at $\mathrm{x}$, south lobe powers in MW:

Nominal Gas Gaps

Cycle 164A $y=-0.1162 x^{2}+17.563 x+56.066$

Cycle 164B $y=-0.1218 x^{2}+17.416 x+56.196$

Hot Gas Gaps

Cycle 164A $y=-0.1303 x^{2}+17.472 x+56.615$

Cycle 164B $y=-0.1096 x^{2}+15.846 x+55.565$ 
These equations can be used to approximate the temperature of any specimen stack at a desired south lobe power with the following steps:

1) Calculate maximum specimen temperature.

2) Calculate scaling factor between nominal and desired lobe power maximum temperatures.

3) Scale all temperatures by calculated factor.

The temperature will lag behind during power changes, especially during rapid power changes, so these equations are representative of a steady state temperature at a given power. It is most appropriate to use the equations associated with the nominal gas gap at the beginning of the irradiation before the materials expand. The equations associated with the hot gas gap are representative of the highest heating rates and temperatures experienced by the capsule. 


\section{CONTENTS}

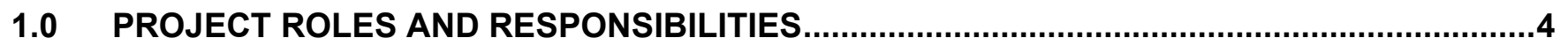

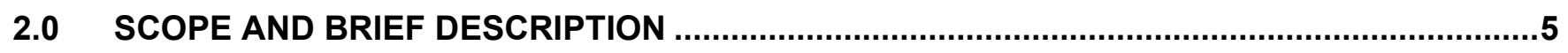

3.0 DESIGN OR TECHNICAL PARAMETER INPUT AND SOURCES .....................................5

4.0 RESULTS OF LITERATURE SEARCHES AND OTHER BACKGROUND DATA......................5

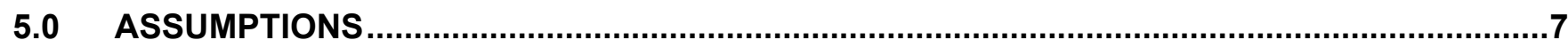

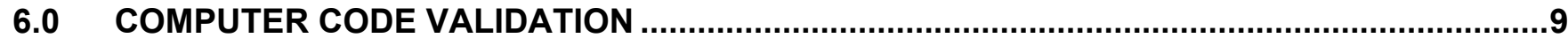

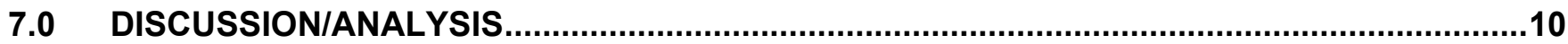

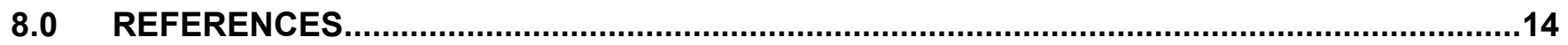

\section{APPENDIXES}

- Appendix A - Material Properties

- Appendix B - Heating Rates

- Appendix C - Heat Transfer Coefficient

- Appendix D - ABAQUS Validation

- Appendix E - Specimen Temperature Results

- Appendix F-Analysis Request 


\subsection{PROJECT ROLES AND RESPONSIBILITIES}

\begin{tabular}{|c|c|c|c|}
\hline Project Role & Name & Organization & Pages Covered (if applicable) \\
\hline Performer & S. M. Wilson & C130 & All \\
\hline Checker $^{a}$ & C. Xing & C130 & All \\
\hline Independent Reviewer ${ }^{b}$ & $\mathrm{~N} / \mathrm{A}$ & ----- & ----- \\
\hline CUI Reviewerc & K. Anderson & ----- & ----- \\
\hline Manager $^{d}$ & M. A. Lillo & C130 & All \\
\hline Requestoref & K. Anderson & C630 & ----- \\
\hline Nuclear Safety ${ }^{f}$ & $\mathrm{~N} / \mathrm{A}$ & ----- & ----- \\
\hline Document Owner ${ }^{f}$ & D. Guillen & B120 & All \\
\hline Reviewer ${ }^{f}$ & $\mathrm{~N} / \mathrm{A}$ & ----- & ----- \\
\hline
\end{tabular}

\section{Responsibilities:}

a. Confirmation of completeness, mathematical accuracy, and correctness of data and appropriateness of assumptions.

b. Concurrence of method or approach. See definition, LWP-10106.

c. Concurrence with the document's markings in accordance with LWP-11202.

d. Concurrence of procedure compliance. Concurrence with method/approach and conclusion.

e. Authorizes the commencement of work of the engineering deliverable. See Appendix A.

f. Concurrence with the document's assumptions and input information. See definition of Acceptance, LWP-10200.

NOTE: Delete or mark "N/A" for project roles not engaged. Include ALL personnel and their roles listed above in the eCR system. The list of the roles above is not all inclusive. If needed, the list can be extended or reduced. 


\subsection{SCOPE AND BRIEF DESCRIPTION}

The purpose of this document is to present the as-run specimen temperature results in support of the CSM-10584 experiment irradiated in position B5 of the ATR for Cycles 164A and 164B. The CSM10584 experiment is performed in conjunction with the Nuclear Science User Facilities (NSUF).

ABAQUS was used to calculate the temperatures and Mathcad was used to calculate the inputs.

\subsection{DESIGN OR TECHNICAL PARAMETER INPUT AND SOURCES}

The requirements for the CSM-10584 experiment were provided in FOR-308 and TFR-966. The actual loading of the holders and capsules were provided in PLN-5306.

As-run heating rates were provided by physics in ECAR-4496.

Heat transfer coefficients and thermal models were provided in ECAR-3626 and ECAR-3672, respectively.

\subsection{RESULTS OF LITERATURE SEARCHES AND OTHER BACKGROUND DATA}

\subsection{Experiment Description}

The CSM-10584 experiment was designed to establish the irradiation performance of stainless steel and Inconel specimens produced using commercially available additive manufacturing techniques under three irradiation considerations:

$325+/-50^{\circ} \mathrm{C}$ at a low dpa (determined by neutronics, one cycle)

$325+/-50^{\circ} \mathrm{C}$ at a medium dpa (determined by neutronics, two cycles)

$325+/-50^{\circ} \mathrm{C}$ at a high dpa (determined by neutronics, two cycles)

All capsules contain both Inconel and stainless steel specimens but have different specimen arrangements within aluminum specimen holders and varying Helium-Argon gas mixtures used to control the specimen temperatures for the desired range. The holders are contained inside stainless steel capsules, which are stacked vertically in a Y-basket with stainless steel spacers used to ensure proper elevation. Capsules $A$ and $B$ at the top of the stack contained only tensile specimens. Capsule $A$ was a low DPA capsule which was removed after the first cycle, but Capsule B was a medium DPA capsule that was irradiated for two cycles. Capsules $D$ and $E$ at the bottom of the stack contained only transmission electron microscope (TEM) specimens for both post-irradiation exam (PIE) and thermophysical property (TPP) testing activities. Capsule D was a medium DPA capsule that was irradiated for two cycles, but Capsule E was a low DPA capsule and was removed after the first cycle. Capsule $\mathrm{C}$, the high DPA capsule, was centered around the core centerline and contained both tensile and TEM specimens. All capsules were designed to specimen temperatures of $325+/-50^{\circ} \mathrm{C}$. 


\subsection{Model Description}

A three-dimensional, steady state heat transfer ABAQUS model was developed for the CSM-10584 programmatic analysis in ECAR-3672. It was considered applicable to this analysis with the following exceptions:

1) The holes in the tensile specimens were removed in Revision 1 of Drawing 605844 for ease of machining. The tensile stacks were regenerated with this design change included.

2) The as-built loading of the tensile specimens in Capsules $A$ and $B$ were different than what was modeled in the programmatic analysis. The materials were switched for the as-run analysis to properly reflect the as-run physics analysis and the loading plan.

Table 1 documents the applicable drawings for the specimens, holder, capsules, basket, and assembly of both the capsules themselves and the entire stackup.

Table 1 - Experiment Component Drawing Numbers and Titles

\begin{tabular}{|c|c|l|}
\hline $\begin{array}{c}\text { Drawing } \\
\text { Number }\end{array}$ & Revision & \multicolumn{1}{c|}{ Drawing Title } \\
\hline 605840 & 3 & $\begin{array}{l}\text { ATR NUCLEAR SCIENCE USER FACILITY (NSUF) CSM-10584 } \\
\text { FIRST CYCLE 164A-1 LOW, MEDIUM AND HIGH DPA } \\
\text { INSTALLATION }\end{array}$ \\
\hline 605842 & 2 & $\begin{array}{l}\text { ATR NUCLEAR SCIENCE USER FACILITY (NSUF) COLORADO } \\
\text { SCHOOL OF MINES (CSM-10584) B5 EXPERIMENT CAPSULES } \\
\text { ASSEMBLIES AND DETAILS }\end{array}$ \\
\hline 605843 & 3 & $\begin{array}{l}\text { ATR NUCLEAR SCIENCE USER FACILITY (NSUF) COLORADO } \\
\text { SCHOOL OF MINES (CSM-10584) B5 EXPERIMENT SPECIMEN } \\
\text { HOLDERS ASSEMBLIES AND DETAILS }\end{array}$ \\
\hline 605844 & 1 & $\begin{array}{l}\text { ATR NUCLEAR SCIENCE USER FACILITY (NSUF) COLORADO } \\
\text { SCHOOL OF MINES (CSM-10584) TENSILE AND TEM SPECIMEN } \\
\text { DETAILS }\end{array}$ \\
\hline 605845 & 1 & $\begin{array}{l}\text { ATR NUCLEAR SCIENCE USER FACILITY (NSUF) CSM-10584 } \\
\text { SECOND CYCLE 164B-1 MEDIUM AND HIGH DPA INSTALLATION }\end{array}$ \\
\hline
\end{tabular}




\subsection{ASSUMPTIONS}

The following assumptions made for the programmatic model are still applicable to the as-built model:

1) Experiment coolant flow rates were determined by hydrodynamic calculations in Mathcad for the thermal safety analysis in ECAR-3626. Since there were no changes to the capsule geometry, they are still considered applicable.

2) The sink temperature for the coolant film condition reflects the inlet temperature with a sensitivity run accounting for the outlet temperatures calculated in the thermal safety analysis in ECAR-3626. If the coolant increased to the maximum allowable inlet temperature, there could be a $9^{\circ} \mathrm{F}\left(5.0^{\circ} \mathrm{C}\right)$ increase in specimen temperatures.

3) Nominal drawing dimensions were used. A sensitivity run in ECAR-3672 determined that specimens manufactured at the lower end of the tolerance could see a $24^{\circ} \mathrm{F}\left(13.3^{\circ} \mathrm{C}\right)$ increase in temperature.

4) The clearance between parts in contact is assumed to be 0.001 inches.

5) The flux and melt wires pictured in the drawing were not discretely included in the analysis. These wires will have a negligible impact on the specimen temperatures. The portion of the holder where these wires are located was modeled as solid aluminum for ease of analysis.

6) Specimens are not assumed to be in contact with the holders. A sensitivity run assuming perfect contact of all parts in ECAR-3672 resulted in a $51^{\circ} \mathrm{F}\left(28.3^{\circ} \mathrm{C}\right)$ decrease in maximum specimen temperature, although a $15^{\circ} \mathrm{C}$ decrease in specimen temperature was assumed to be more realistic.

7) Radiation heat transfer was not considered as conduction across gas gaps and material contact has the largest impact on specimen temperatures.

Additional assumptions for the as-run model are as follows:

1) The drawings associated with the experiment have been revised various times. The largest change from the programmatic analysis in ECAR-3672 was the removal of the holes in the tensile specimens, but there are other minor changes with negligible impact on the temperatures of the specimens. The spacers, standoff, capsule tube length, and capsule cap length are all slightly different from the drawings, but would have no impact on the specimen temperatures since no heat loads or convection coefficients have an axial distribution. The PIE TEM basket, specimen container tube, and specimen container cap all have variations from the drawings, but not significantly impact the specimen temperatures. None of these minor differences are included in the model.

2) Since there was no change in part dimensions or locations, the heat transfer coefficients calculated in Appendix C of ECAR-3672 were considered applicable to the as-run analysis. 
3) Additional gap conductance values for hot gas gaps were calculated. Analyses were performed for both nominal and hot gas gaps for the capsule to ensure the temperatures through the entirety of the irradiation can be determined.

4) The actual temperature history of the specimens was not provided as a transient analysis. Although the temperatures would lag behind the reactor power, steady state temperature values at various power fractions were calculated to generate an equation to estimate the temperature. This approach was deemed acceptable by the program. 


\subsection{COMPUTER CODE VALIDATION}

The finite element heat transfer thermal analysis of the CSM-10584 As-Run experiment was performed using ABAQUS version 6.14-2 on an Intel@ Core $^{\mathrm{TM}} \mathrm{i} 7-8850 \mathrm{H}$ CPU @ $2.60 \mathrm{GHz}$ machine with $16 \mathrm{~GB}$ of RAM.

ABAQUS is listed in the INL Enterprise Architecture (EA) repository of qualified scientific and engineering analysis software (EA Identifier 336418). ABAQUS has been validated for the thermal analysis of ATR experiments by solving several test problems and verifying the results against analytical solutions provided in heat transfer text books. A complete description of the validation test problems is given in ECAR-131. Scripts were developed to automate the execution, data collection, and relative error calculation for each test problem. The scripts were run on a local computer named INL608356 and a report file containing the validation test results was generated automatically. The results meet the acceptance criterion that the relative error is less than $3 \%$. The report is provided as Appendix $\mathrm{C}$ of this document.

Calculations given in the appendices were performed using PTC Mathcad Prime 3.0 and Microsoft Excel. Formal validation of Mathcad and spreadsheet applications is not required, instead random hand calculations are performed during checking to verify that the computer-generated output is correct, as discussed in Appendix E in LWP-10200.

The ABAQUS files containing the models created for this analysis are stored in IIfswcb1|PROJECTSIUSUFIRRADIATION TESTINGIC660 AnalystsIStacey WilsonICSM_AsRun. The files created are listed in Table 2.

Table 2 - ABAQUS/CAE Models, and Input and Output File

\begin{tabular}{|c|c|}
\hline File Name & Description \\
\hline $\begin{array}{c}\text { CSM_AsRun.cae } \\
\text { CSM_AsRun.jnl }\end{array}$ & Model for the two cycles the CSM experiment was irradiated \\
\hline $\begin{array}{c}\text { CSM-AsRun-Nominal.inp } \\
\text { CSM-AsRun-Nominal.odb }\end{array}$ & $\begin{array}{r}\text { Nominal power (100\%) results for the two cycles the CSM } \\
\text { experiment was irradiated }\end{array}$ \\
\hline $\begin{array}{c}\text { CSM-AsRun-Powxx.inp } \\
\text { CSM-AsRun-Powxx.odb }\end{array}$ & $\begin{array}{r}\text { Results for the two cycles the CSM experiment was irradiated, } \\
\text { where xx stands for the analyzed powers of } 10 \%, 25 \%, 50 \%, \\
60 \%, 70 \%, 80 \%, 90 \%, 110,120 \%\end{array}$ \\
\hline $\begin{array}{c}\text { CSM-AsRun-HGG-Nominal.inp } \\
\text { CSM-AsRun-HGG-Nominal.odb }\end{array}$ & $\begin{array}{r}\text { Nominal power (100\%) results for the two cycles the CSM } \\
\text { experiment was irradiated using hot gas gaps }\end{array}$ \\
\hline $\begin{array}{c}\text { CSM-AsRun-HGG-Powx.inp } \\
\text { CSM-AsRun-HGG-Powxx.odb }\end{array}$ & $\begin{array}{r}\text { Results for the two cycles the CSM experiment was irradiated } \\
\text { using hot gas gaps, where xx stands for the analyzed powers } \\
\text { of 10\%, 25\%, 50\%, 60\%, 70\%, 80\%, 90\%, 110,120\% }\end{array}$ \\
\hline
\end{tabular}




\subsection{DISCUSSION/ANALYSIS}

\subsection{Experiment Description}

\section{Geometry}

As previously stated, a three-dimensional ABAQUS model was developed for the programmatic analysis in ECAR-3672. It used the 8-node linear brick element to model all components.

The only changes to the programmatic model geometry for use with the as-run analysis was the removal of the tensile specimen holes and switching the materials for the Capsule A and B tensile specimens to match the loading plan and physics analysis.

\section{$\underline{\text { Steps }}$}

Two analysis steps were created for the as-run analysis. Step 1 represents Cycle 164A and Step 2 represents Cycle 164B.

\section{Interactions and Constraints}

The interactions and constraints for the programmatic model were unchanged for the as-run model. The interaction properties for the nominal gas gaps and the inputs for calculating the gap conductance of the hot gas gap were unchanged for the as-run model, although additional hot gas gap conductance values were calculated in this ECAR to cover all gas mixtures used in the experiment.

\section{Amplitude}

The amplitude PowFraction was used to scale all the heat loads to the appropriate power fraction being analyzed.

\section{Heat Loads}

The as-run heat loads were provided by physics in ECAR-4496 at nominal core power configurations (22.5 MW and 22.6 MW south source lobe power) for Cycles 164A and 164B, respectively. The heat loads were converted from W/g to BTU/s-in ${ }^{3}$ in Appendix $B$ for use in ABAQUS.

To model the removal of Capsules $A$ and $E$ for Cycle 164B, the heat loads for all components in those capsules were set to $0 \mathrm{BTU} / \mathrm{s}-\mathrm{in}^{3}$.

It should be noted that the capsule designations $(A, B, C, D, E)$ are consistent between the physics and thermal analysis despite the differing arrangement of results in the tables. 


\subsection{Experiment Description}

\section{Nominal Gas Gap Results}

The specimen temperatures at nominal power with a nominal gas gap are 263 to $392^{\circ} \mathrm{C}$ and 266 to $387^{\circ} \mathrm{C}$ for Cycles $164 \mathrm{~A}$ and $164 \mathrm{~B}$, respectively. The temperatures by specimen stack are detailed in Appendix E.

The maximum temperature at various power level for each cycle are provided below in Table 3. Note that the removal of Capsules $A$ and $E$ for Cycle 164B cause the maximum temperature in Cycle 164A to be in the Capsule A tensile specimens and the maximum temperature in Cycle 164B to be in the Capsule B tensile specimens.

\section{Table 3 - Maximum Specimen Temperatures at Various Power Levels}

\begin{tabular}{|c|c|c|c|c|c|c|}
\hline \multirow{2}{*}{$\begin{array}{c}\text { Power } \\
\text { Fraction }\end{array}$} & \multicolumn{3}{|c|}{ Cycle 164A } & \multicolumn{3}{c|}{ Cycle 164B } \\
\cline { 2 - 7 } & Power (MW) & ${ }^{\circ} \mathrm{F}$ & ${ }^{\circ} \mathrm{C}$ & Power (MW) & ${ }^{\circ} \mathrm{F}$ & ${ }^{\circ} \mathrm{C}$ \\
\hline 0.1 & 2.25 & 201 & 94 & 2.26 & 201 & 94 \\
\hline 0.25 & 5.63 & 306 & 152 & 5.65 & 305 & 152 \\
\hline 0.5 & 11.25 & 464 & 240 & 11.30 & 461 & 238 \\
\hline 0.6 & 13.50 & 522 & 272 & 13.56 & 519 & 271 \\
\hline 0.7 & 15.75 & 579 & 304 & 15.82 & 574 & 301 \\
\hline 0.8 & 18.00 & 633 & 334 & 18.08 & 627 & 331 \\
\hline 0.9 & 20.25 & 686 & 363 & 20.34 & 679 & 359 \\
\hline 1 & 22.50 & 737 & 392 & 22.60 & 728 & 387 \\
\hline 1.1 & 24.75 & 787 & 419 & 24.86 & 777 & 414 \\
\hline 1.2 & 27.00 & 836 & 447 & 27.12 & 824 & 440 \\
\hline
\end{tabular}

These values were graphed in Appendix E. The $2^{\text {nd }}$ order polynomial equations that can be used to calculate the maximum specimen temperatures $\left({ }^{\circ} \mathrm{C}\right), \mathrm{y}$, at south lobe powers $(\mathrm{MW}), \mathrm{x}$, are as follows:

$$
\begin{array}{ll}
\text { Cycle 164A } & y=-0.1162 x^{2}+17.563 x+56.066 \\
\text { Cycle 164B } & y=-0.1218 x^{2}+17.416 x+56.196
\end{array}
$$

These equations can be used to approximate the temperature of any specimen stack at a desired south lobe power with the following steps:

1) Calculate maximum specimen temperature.

2) Calculate scaling factor between nominal and desired lobe power maximum temperatures.

3) Scale all temperatures by calculated factor.

It should be noted again that the temperature will lag behind the power, especially during rapid power changes, so these equations are representative of a steady state temperature. 


\section{Hot Gas Gap Results}

The specimen temperatures at nominal power with a hot gas gap for the capsule interactions are 237 to $383^{\circ} \mathrm{C}$ and 249 to $357^{\circ} \mathrm{C}$ for Cycles $164 \mathrm{~A}$ and $164 \mathrm{~B}$, respectively. The temperatures by specimen stack are detailed in Appendix E.

The maximum temperature at various power level for each cycle are provided below in Table 4 . Note that the removal of Capsules $\mathrm{A}$ and $\mathrm{E}$ for Cycle 164B cause the maximum temperature in Cycle 164A to be in the Capsule $A$ tensile specimens and the maximum temperature in Cycle 164B to be in the Capsule B tensile specimens.

Table 4 - Maximum Specimen Temperatures at Various Power Levels

\begin{tabular}{|c|c|c|c|c|c|c|}
\hline \multirow{2}{*}{$\begin{array}{c}\text { Power } \\
\text { Fraction }\end{array}$} & \multicolumn{3}{|c|}{ Cycle 164A } & \multicolumn{3}{c|}{ Cycle 164B } \\
\cline { 2 - 7 } & Power (MW) & ${ }^{\circ} \mathrm{F}$ & ${ }^{\circ} \mathrm{C}$ & Power (MW) & ${ }^{\circ} \mathrm{F}$ & ${ }^{\circ} \mathrm{C}$ \\
\hline 0.1 & 2.25 & 201 & 94 & 2.26 & 194 & 90 \\
\hline 0.25 & 5.63 & 306 & 152 & 5.65 & 288 & 142 \\
\hline 0.5 & 11.25 & 460 & 238 & 11.30 & 431 & 222 \\
\hline 0.6 & 13.50 & 516 & 269 & 13.56 & 483 & 251 \\
\hline 0.7 & 15.75 & 571 & 299 & 15.82 & 534 & 279 \\
\hline 0.8 & 18.00 & 623 & 328 & 18.08 & 582 & 306 \\
\hline 0.9 & 20.25 & 673 & 356 & 20.34 & 629 & 332 \\
\hline 1 & 22.50 & 721 & 383 & 22.60 & 675 & 357 \\
\hline 1.1 & 24.75 & 769 & 409 & 24.86 & 719 & 382 \\
\hline 1.2 & 27.00 & 814 & 434 & 27.12 & 762 & 406 \\
\hline
\end{tabular}

These values were graphed in Appendix $\mathrm{E}$. The $2^{\text {nd }}$ order polynomial equations that can be used to calculate the maximum specimen temperatures $\left({ }^{\circ} \mathrm{C}\right), y$, at south lobe powers $(\mathrm{MW}), \mathrm{x}$, are as follows:

Cycle 164A $y=-0.1303 x^{2}+17.472 x+56.615$

Cycle 164B $y=-0.1096 x^{2}+15.846 x+55.565$

These equations can be used to approximate the temperature of any specimen stack at a desired south lobe power with the following steps:

1) Calculate maximum specimen temperature.

2) Calculate scaling factor between nominal and desired lobe power maximum temperatures.

3) Scale all temperatures by calculated factor.

It should be noted again that the temperature will lag behind the power, especially during rapid power changes, so these equations are representative of a steady state temperature. 


\section{$\underline{\text { Conclusion }}$}

The specimen temperatures at nominal power and nominal gas gaps are between 263 to $392^{\circ} \mathrm{C}$ for Cycle $164 \mathrm{~A}$ and 266 to $387^{\circ} \mathrm{C}$ for Cycle $164 \mathrm{~B}$. The specimen temperatures at nominal power and capsule hot gas gaps are between 237 to $383^{\circ} \mathrm{C}$ for Cycle $164 \mathrm{~A}$ and 249 to $357^{\circ} \mathrm{C}$ for Cycle $164 \mathrm{~B}$. Detailed nominal power temperatures are in Appendix E. Tables E1 through E4 report the temperatures for stacks of specimens, not individual specimens. To ensure that the temperatures are applied to the correct specimens, Table E5 provides the specimen numbers associated with each specimen stack as documented in PLN-5306.

The maximum temperature at various power level for each cycle at nominal gas gaps and hot gas gaps was calculated and graphed in Appendix E. The data was fit with the following $2^{\text {nd }}$ order polynomial equations used to calculate $y$, the maximum specimen temperatures $\left({ }^{\circ} \mathrm{C}\right)$, at $\mathrm{x}$, south lobe powers in MW:

Nominal Gas Gaps

$$
\begin{array}{ll}
\text { Cycle 164A } & y=-0.1162 x^{2}+17.563 x+56.066 \\
\text { Cycle 164B } & y=-0.1218 x^{2}+17.416 x+56.196
\end{array}
$$

Hot Gas Gaps

$$
\begin{array}{ll}
\text { Cycle 164A } & y=-0.1303 x^{2}+17.472 x+56.615 \\
\text { Cycle 164B } & y=-0.1096 x^{2}+15.846 x+55.565
\end{array}
$$

These equations can be used to approximate the temperature of any specimen stack at a desired south lobe power with the following steps:

1) Calculate maximum specimen temperature.

2) Calculate scaling factor between nominal and desired lobe power maximum temperatures.

3) Scale all temperatures by calculated factor.

The temperature will lag behind during power changes, especially during rapid power changes, so these equations are representative of a steady state temperature at a given power. It is most appropriate to use the equations associated with the nominal gas gap at the beginning of the irradiation before the materials expand. The equations associated with the hot gas gap are representative of the highest heating rates and temperatures experienced by the capsule. 


\subsection{REFERENCES}

1. FOR-308, Revision 1, "Colorado School of Mines (CSM-10584)," April 2017.

2. TFR-966, "Colorado School of Mines (CSM)-10584 ATR ADDITIVE MATERIALS EXPERIMENT," May 2017.

3. PLN-5306, Revision 1, "CSM-10584 Loading and Marking Arrangement," February 2019.

4. ECAR-4496, Revision 1, "AS-RUN NEUTRONICS EVALUATION FOR THE CSM-10584 EXPERIMENT IN THE ATR,” J. Mitchell, October 2020.

5. ECAR-3626, Revision 1, "Thermal and Structural Safety Compliance Analysis for a Non-Fueled Drop-In Experiment in a Small B Position," C. Hale, June 2017.

6. ECAR-3672, "Programmatic Thermal Analysis for the CSM-10584 Experiment," S. M. Wilson, July 2017.

7. ECAR-131, "Validation of ABAQUS Standard 6.7-3 Heat Transfer," P. E. Murray, January 2008.

8. PG-T-91-031, "Thermophysical and Mechanical Properties of ATR Core Materials," S. T. Polkinghorne, J. M. Lacy, August 1991.

9. ASM Handbook, Volume 1, http://products.asminternational.org/hbk/index.jsp.

10. ASM Handbook, Volume 2, http://products.asminternational.org/hbk/index.jsp.

11. CINDAS Thermophysical Properties of Matter Database (TPMD), https://cindasdata.com/Applications/TPMD/. 


\begin{tabular}{|lrr|}
\hline $\begin{array}{l}\text { TEM-10200-1, Rev. } 11 \\
11 / 20 / 2019\end{array}$ & ENGINEERING CALCULATIONS AND ANALYSIS & ECAR-4907, Rev. 0 \\
& As-Run Thermal Analysis for the CSM-10584 Experiment & of A2 \\
\hline
\end{tabular}

\section{Appendix A - Material Properties}

\section{Aluminum 6061-T6}

From Tables 3.1 and 3.2 in: S. T. Polkinghorne, J. M. Lacy, "Thermophysical and Mechanical Properties of ATR Core Materials," EG\&G Internal Technical Report, PG-T-91-031, August 1991

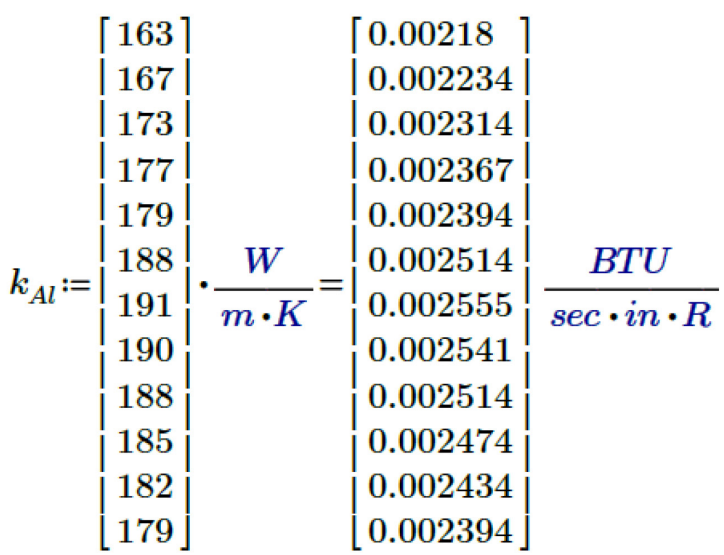

$T_{A l_{-} c p}:=\left[\begin{array}{l}290 \\ 400 \\ 500 \\ 600 \\ 700 \\ 800\end{array}\right] \cdot K=\left[\begin{array}{r}62.33 \\ 260.33 \\ 440.33 \\ 620.33 \\ 800.33 \\ 980.33\end{array}\right]$

$\rho_{A l}:=2702 \cdot \frac{k g}{m^{3}}=0.098 \frac{l b}{i n^{3}}$

$$
\alpha_{A l}:=25.4 \cdot 10^{-6} \cdot \frac{1}{\Delta^{\circ} \mathrm{C}}
$$

$c_{p \_A l}:=\left[\begin{array}{c}896 \\ 942 \\ 988 \\ 1034 \\ 1080 \\ 1126\end{array}\right] \cdot \frac{J}{k g \cdot K}=\left[\begin{array}{l}0.214 \\ 0.225 \\ 0.236 \\ 0.247 \\ 0.258 \\ 0.269\end{array}\right] \frac{B T U}{l b \cdot R}$

Maximum temperature in range is close to the target temperatures of the capsule $\left(300^{\circ} \mathrm{C}\right)$. 


\section{4 and 316 Stainless Steel}

ASM Handbook Volume 1, Properties and Selection: Irons, Steels, and High-Peformance Alloys, Specialty Steels and Heat-Resistant Alloys, Wrought Stainless Steels, Physical

Properties, Table 21.

$$
\begin{array}{ll}
T_{S S_{-} k}:=\left[\begin{array}{l}
100 \\
500
\end{array}\right]{ }^{\circ} \mathrm{C}=\left[\begin{array}{l}
212 \\
932
\end{array}\right]{ }^{\circ} \mathrm{F} & k_{S S}:=\left[\begin{array}{l}
16.2 \\
21.5
\end{array}\right] \cdot \frac{\mathrm{W}}{\mathrm{m} \cdot \mathrm{K}}=\left[\begin{array}{l}
2.167 \cdot 10^{-4} \\
2.876 \cdot 10^{-4}
\end{array}\right] \frac{\mathrm{BTU}}{\mathrm{sec} \cdot \mathrm{in} \cdot \mathrm{R}} \\
c_{p_{-} S S}:=500 \cdot \frac{\mathrm{J}}{\mathrm{kg} \cdot \mathrm{K}}=0.119 \frac{\mathrm{BTU}}{\mathrm{lb} \cdot \mathrm{R}} & \\
\rho_{S S}:=8.0 \cdot \frac{\mathrm{gm}}{\mathrm{cm}^{3}}=0.289 \frac{\mathrm{lb}}{\mathrm{in}^{3}} & \text { For } \mathrm{SS} 304 \text { at } 100^{\circ} \mathrm{C} \\
\alpha_{S S}:=17.2 \cdot 10^{-6} \cdot \frac{1}{\Delta^{\circ} \mathrm{C}} &
\end{array}
$$

\section{Inconel (Nickel Alloy 718)}

ASM Handbook Volume 2, Properties and Selection: Nonferrous Alloys and SpecialPurpose Materials, Specific Metals and Alloys, Nickel and Nickel Alloys, Commercial Nickel and Nickel Alloys, Table 6.

$$
\begin{aligned}
& k_{\text {Inc }}:=11.4 \cdot \frac{W}{\mathrm{~m} \cdot K}=0.000152 \frac{\mathrm{BTU}}{\mathrm{sec} \cdot \mathrm{in} \cdot R} \\
& c_{p_{-} I n c}:=435 \cdot \frac{\mathrm{J}}{\mathrm{kg} \cdot \mathrm{K}}=0.104 \frac{\mathrm{BTU}}{\mathrm{lb} \cdot \mathrm{R}} \\
& \rho_{\text {Inc }}:=8.19 \cdot \frac{\mathrm{gm}}{\mathrm{cm}^{3}}=0.296 \frac{\mathrm{lb}}{\mathrm{in}^{3}}
\end{aligned}
$$




\section{Appendix B - Heating Rates}

Heating Rates provided by physics in Table 8 of ECAR-4496 are oriented from the bottom of the core to the top. Capsule $E$ is the bottom capsule in the experiment stackup and Capsule $A$ is the top. Capsules A2, B2, C3, C4, D2 and E2 contain inconel specimens, the other capsules contain stainless steel specimens. For ease of calculating the ABAQUS input, the heating rates are oragnized as followed:

TEMSpecimens $:=\left[\begin{array}{l}\text { "PIE Disc Stack 1" } \\ \text { "PIE Disc Stack 2" } \\ \text { "PIE Disc Stack 3" } \\ \text { "PIE Disc Stack 4" } \\ \text { "TPP Disc Stack" }\end{array}\right]$

TEMBasket_Holder $:=\left[\begin{array}{c}\text { "PIE Basket" } \\ \text { "TPP Basket" } \\ \text { "Specimen Holder" }\end{array}\right]$

TensileSpecimens := "Tensile Sample Smear"

TensileSpacer_Holder $:=\left[\begin{array}{c}\text { "Tensile Spacers" } \\ \text { "Specimen Holder" }]\end{array}\right]$ 
The heating rates are provided in two columns to represent the two irradiation cycles, Cycle $164 \mathrm{~A}$ at $22.5 \mathrm{MW}$ and Cycle 164B at $22.6 \mathrm{MW}$ south source power. Those capsules and samples not irradiated in Cycle 164B have a heating rate of 0 in the second column.

$$
\text { HRs := ["Cycle164A" "Cycle164B"] }
$$

\section{Capsule A Heating Rates}

A1_TensileSpecimens $:=\left[\begin{array}{ll}1.3 & 0\end{array}\right] \cdot \frac{W}{g m}$

$$
A 1 \_T e n s i l e H R:=A 1 \_T e n s i l e S p e c i m e n s \cdot \rho_{S S}=\left[\begin{array}{ll}
0.162 & 0
\end{array}\right] \frac{B T U}{s \cdot i n^{3}}
$$

A1_SpacerEHHolder $:=\left[\begin{array}{ll}0.9 & 0 \\ 1.1 & 0\end{array}\right] \cdot \frac{W}{g m}$

$$
\text { A1_SpacerधHolderHR }:=A 1 \_S p a c e r \xi H o l d e r \cdot \rho_{A l}=\left[\begin{array}{ll}
0.038 & 0.000 \\
0.046 & 0.000
\end{array}\right] \frac{B T U}{s \cdot i n^{3}}
$$

A2_TensileSpecimens $:=\left[\begin{array}{ll}1.8 & 0\end{array}\right] \cdot \frac{W}{g m}$

$A 2 \_T e n s i l e H R:=A 2 \_T e n s i l e S p e c i m e n s \cdot \rho_{I n c}=\left[\begin{array}{ll}0.229 & 0\end{array}\right] \frac{B T U}{s \cdot i n^{3}}$

A2_SpacerEHHolder $:=\left[\begin{array}{ll}1.3 & 0 \\ 1.4 & 0\end{array}\right] \cdot \frac{W}{g m}$

A2_SpacerEHolderHR $:=A 2 \_S p a c e r \xi H o l d e r \cdot \rho_{A l}=\left[\begin{array}{ll}0.055 & 0.000 \\ 0.059 & 0.000\end{array}\right] \frac{B T U}{s^{*} i n^{3}}$

CapsuleA $:=\left[\begin{array}{ll}1.6 & 0\end{array}\right] \cdot \frac{W}{g m} \quad$ CapsuleAHR $:=$ CapsuleA $\cdot \rho_{S S}=\left[\begin{array}{ll}0.199 & 0\end{array}\right] \frac{B T U}{s \cdot i n^{3}}$ 


\section{Capsule B Heating Rates}

B1_TensileSpecimens $:=\left[\begin{array}{ll}2.2 & 2.2\end{array}\right] \cdot \frac{W}{g m}$

$B 1 \_T e n s i l e H R:=B 1 \_T e n s i l e S p e c i m e n s \cdot \rho_{S S}=\left[\begin{array}{ll}0.273 & 0.273\end{array}\right] \frac{B T U}{s \cdot i n^{3}}$

B1_SpacerEHolder $:=\left[\begin{array}{ll}1.7 & 1.7 \\ 1.8 & 1.9\end{array}\right] \cdot \frac{W}{g m}$

B1_SpacerEHolderHR $:=B 1 \_S p a c e r \& H o l d e r \cdot \rho_{A l}=\left[\begin{array}{ll}0.071 & 0.071 \\ 0.076 & 0.080\end{array}\right] \frac{B T U}{s \cdot \text { in }^{3}}$

B2_TensileSpecimens $:=\left[\begin{array}{ll}2.9 & 2.9\end{array}\right] \cdot \frac{W}{g m}$

$B 2 \_T e n s i l e H R:=B 2 \_T e n s i l e S p e c i m e n s \cdot \rho_{I n c}=\left[\begin{array}{ll}0.369 & 0.369\end{array}\right] \frac{B T U}{s \cdot i n^{3}}$

B2_SpacerEHolder $:=\left[\begin{array}{ll}2.0 & 2.0 \\ 2.2 & 2.2\end{array}\right] \cdot \frac{W}{g m}$

B2_SpacerEHolderHR $:=B 2 \_S p a c e r E H$ Holder $\cdot \rho_{A l}=\left[\begin{array}{ll}0.084 & 0.084 \\ 0.092 & 0.092\end{array}\right] \frac{B T U}{s \cdot i^{3}}$

CapsuleB $:=\left[\begin{array}{ll}2.6 & 2.6\end{array}\right] \cdot \frac{W}{g m} \quad$ CapsuleBHR $:=$ CapsuleB $\cdot \rho_{S S}=\left[\begin{array}{ll}0.323 & 0.323\end{array}\right] \frac{B T U}{s \cdot i n^{3}}$ 
Capsule C Heating Rates

$C 1 \_$TEMSpecimens $:=\left[\begin{array}{cc}7.6 & 7.6 \\ 7.7 & 7.7 \\ 7.2 & 7.3 \\ 7.3 & 7.3 \\ 7.4 & 7.4\end{array}\right] \cdot \frac{W}{g m}$

$C 1 \_T E M H R:=C 1 \_T E M S p e c i m e n s \cdot \rho_{S S}=\left[\begin{array}{ll}0.944 & 0.944 \\ 0.957 & 0.957 \\ 0.895 & 0.907 \\ 0.907 & 0.907 \\ 0.919 & 0.919\end{array}\right] \frac{B T U}{s \cdot i^{3}}$

$C 1 \_$Holder $:=\left[\begin{array}{ll}7.6 & 7.6 \\ 6.8 & 6.8 \\ 5.9 & 5.9\end{array}\right] \cdot \frac{W}{g m}$

$C 1 \_H o l d e r H R:=C 1 \_H o l d e r \cdot \rho_{A l}=\left[\begin{array}{ll}0.319 & 0.319 \\ 0.285 & 0.285 \\ 0.248 & 0.248\end{array}\right] \frac{B T U}{\mathrm{~s} \cdot \mathrm{in}^{3}}$

$C 2 \_$TensileSpecimens $:=\left[\begin{array}{ll}7.3 & 7.3\end{array}\right] \cdot \frac{W}{g m}$

$C 2 \_T e n s i l e H R:=C 2 \_T e n s i l e S p e c i m e n s \cdot \rho_{S S}=\left[\begin{array}{lll}0.907 & 0.907\end{array}\right] \frac{B T U}{s \cdot i n^{3}}$

$C 2 \_$Spacer\&Holder $:=\left[\begin{array}{ll}5.7 & 5.8 \\ 5.9 & 6.0\end{array}\right] \cdot \frac{W}{g m}$

$C 2 \_S p a c e r \& H$ HolderHR $:=C 2 \_$Spacer 8 Holder $\cdot \rho_{A l}=\left[\begin{array}{ll}0.239 & 0.243 \\ 0.248 & 0.252\end{array}\right] \frac{B T U}{s \cdot \text { in }^{3}}$

C3_TensileSpecimens $:=\left[\begin{array}{ll}8.0 & 8.0\end{array}\right] \cdot \frac{W}{g m}$

$C 3 \_T e n s i l e H R:=C 3 \_$TensileSpecimens $\cdot \rho_{\text {Inc }}=\left[\begin{array}{ll}1.018 & 1.018\end{array}\right] \frac{B T U}{s \cdot i n^{3}}$ 


\begin{tabular}{|llr|}
\hline TEM-10200-1, Rev. 11 & ENGINEERING CALCULATIONS AND ANALYSIS & ECAR-4907, Rev. 0 \\
& Ps-Run Thermal Analysis for the CSM-10584 Experiment & \\
\hline
\end{tabular}

C3_Spacer $\mathcal{E} H$ Holder $:=\left[\begin{array}{ll}5.8 & 5.8 \\ 6.0 & 6.0\end{array}\right] \cdot \frac{W}{g m}$

$C 3 \_$SpacerEHHolderHR $:=C 3 \_S p a c e r E H$ Holder $\cdot \rho_{A l}=\left[\begin{array}{ll}0.243 & 0.243 \\ 0.252 & 0.252\end{array}\right] \frac{B T U}{s \cdot \text { in }^{3}}$

C4_TEMSpecimens $:=\left[\begin{array}{ll}8.4 & 8.5 \\ 8.4 & 8.5 \\ 7.9 & 8.0 \\ 8.3 & 8.3 \\ 8.2 & 8.3\end{array}\right] \cdot \frac{W}{g m}$

$C 4 \_T E M H R:=C 4 \_T E M S p e c i m e n s \cdot \rho_{\text {Inc }}=\left[\begin{array}{ll}1.069 & 1.081 \\ 1.069 & 1.081 \\ 1.005 & 1.018 \\ 1.056 & 1.056 \\ 1.043 & 1.056\end{array}\right] \frac{B T U}{s \cdot i^{3}}$

$C 4 \_$Holder $:=\left[\begin{array}{cc}7.6 & 7.6 \\ 6.9 & 6.9 \\ 6.0 & 6.0\end{array}\right] \cdot \frac{W}{g m}$

$C 4 \_$HolderHR $:=C 4 \_$Holder $\cdot \rho_{A l}=\left[\begin{array}{cc}0.319 & 0.319 \\ 0.290 & 0.290 \\ 0.252 & 0.252\end{array}\right] \frac{B T U}{s \cdot i^{3}}$

CapsuleC $:=\left[\begin{array}{ll}8.0 & 8.0\end{array}\right] \cdot \frac{W}{g m} \quad$ CapsuleCHR $:=$ CapsuleC $\cdot \rho_{S S}=\left[\begin{array}{lll}0.994 & 0.994\end{array}\right] \frac{B T U}{s \cdot i n^{3}}$ 
Capsule D Heating Rates

$D 1 \_$TEMSpecimens $:=\left[\begin{array}{ll}3.1 & 3.2 \\ 3.2 & 3.2 \\ 3.1 & 3.1 \\ 3.0 & 3.1 \\ 3.3 & 3.3\end{array} \mid \cdot \frac{W}{g m}\right.$

$D 1 \_T E M H R:=D 1 \_T E M S p e c i m e n s \cdot \rho_{S S}=\left[\begin{array}{cc}0.385 & 0.398 \\ 0.398 & 0.398 \\ 0.385 & 0.385 \\ 0.373 & 0.385 \\ 0.410 & 0.410\end{array}\right] \frac{B T U}{s \cdot n^{3}}$

$D 1 \_$Holder $:=\left[\begin{array}{ll}3.2 & 3.2 \\ 3.0 & 3.0 \\ 2.6 & 2.6\end{array}\right] \cdot \frac{W}{g m}$

$D 1 \_$HolderHR $:=D 1 \_$Holder $\cdot \rho_{A l}=\left[\begin{array}{ll}0.134 & 0.134 \\ 0.126 & 0.126 \\ 0.109 & 0.109\end{array}\right] \frac{B T U}{s \cdot i n^{3}}$

$D 2 \_T E M S p e c i m e n s:=\left[\begin{array}{ll}3.1 & 3.1 \\ 3.2 & 3.2 \\ 2.9 & 2.9 \\ 2.9 & 2.9 \\ 3.2 & 3.2\end{array}\right] \cdot \frac{W}{g m}$

$D 2 \_T E M H R:=D 2 \_T E M S p e c i m e n s \cdot \rho_{\text {Inc }}=\left[\begin{array}{cc}0.394 & 0.394 \\ 0.407 & 0.407 \\ 0.369 & 0.369 \\ 0.369 & 0.369 \\ 0.407 & 0.407\end{array}\right] \frac{B T U}{s \cdot i n^{3}}$

$D 2 \_$Holder $:=\left[\begin{array}{ll}2.8 & 2.8 \\ 2.6 & 2.7 \\ 2.3 & 2.3\end{array}\right] \cdot \frac{W}{g m}$

$D 2 \_H o l d e r H R:=D 2 \_H o l d e r \cdot \rho_{A l}=\left[\begin{array}{ll}0.118 & 0.118 \\ 0.109 & 0.113 \\ 0.097 & 0.097\end{array}\right] \frac{B T U}{s \cdot i^{3}}$

CapsuleD $:=\left[\begin{array}{ll}3.3 & 3.3\end{array}\right] \cdot \frac{W}{g m} \quad$ CapsuleDHR:=CapsuleD $\cdot \rho_{S S}=\left[\begin{array}{ll}0.41 & 0.41\end{array}\right] \frac{B T U}{s \cdot i n^{3}}$ 
Capsule E Heating Rates

E1_TEMSpecimens $:=\left[\begin{array}{ll}2.3 & 0 \\ 2.3 & 0 \\ 2.1 & 0 \\ 2.1 & 0 \\ 2.3 & 0\end{array}\right] \cdot \frac{W}{g m}$

E1_TEMHR $:=E 1 \_T E M S p e c i m e n s \cdot \rho_{S S}=\left[\begin{array}{cc}0.286 & 0.000 \\ 0.286 & 0.000 \\ 0.261 & 0.000 \\ 0.261 & 0.000 \\ 0.286 & 0.000\end{array}\right] \frac{B T U}{s \cdot i n^{3}}$

E1_Holder $:=\left[\begin{array}{ll}2.2 & 0 \\ 2.1 & 0 \\ 1.8 & 0\end{array}\right] \cdot \frac{W}{g m}$

E1_HolderHR $:=E 1 \_H o l d e r \cdot \rho_{A l}=\left[\begin{array}{ll}0.092 & 0.000 \\ 0.088 & 0.000 \\ 0.076 & 0.000\end{array}\right] \frac{B T U}{s \cdot i n^{3}}$

E2_TEMSpecimens $:=\left[\begin{array}{ll}2.0 & 0 \\ 2.0 & 0 \\ 2.0 & 0 \\ 2.0 & 0 \\ 2.2 & 0\end{array}\right] \cdot \frac{W}{g m}$

E2_TEMHR $:=E 2 \_T E M S p e c i m e n s \cdot \rho_{\text {Inc }}=\left[\begin{array}{cc}0.254 & 0.000 \\ 0.254 & 0.000 \\ 0.254 & 0.000 \\ 0.254 & 0.000 \\ 0.280 & 0.000\end{array}\right] \frac{B T U}{s \cdot i n^{3}}$

E2_Holder $:=\left[\begin{array}{ll}1.8 & 0 \\ 1.7 & 0 \\ 1.5 & 0\end{array}\right] \cdot \frac{W}{g m}$

$E 2 \_$HolderHR $:=E 2 \_H o l d e r \cdot \rho_{A l}=\left[\begin{array}{ll}0.076 & 0.000 \\ 0.071 & 0.000 \\ 0.063 & 0.000\end{array}\right] \frac{B T U}{s \cdot i^{3}}$

CapsuleE $:=\left[\begin{array}{ll}2.3 & 0\end{array}\right] \cdot \frac{W}{g m} \quad$ CapsuleEHR $:=$ CapsuleE $\cdot \rho_{S S}=\left[\begin{array}{ll}0.286 & 0\end{array}\right] \frac{B T U}{s \cdot i n^{3}}$ 
Spacer Heating Rates

TopSpacer $:=\left[\begin{array}{ll}5.4 & 5.4\end{array}\right] \cdot \frac{W}{g m}$

$$
\text { TopSpacerHR:=TopSpacer } \cdot \rho_{S S}=\left[\begin{array}{ll}
0.671 & 0.671
\end{array}\right] \frac{B T U}{s \cdot i n^{3}}
$$

BottomSpacer $:=\left[\begin{array}{ll}5.7 & 5.7\end{array}\right] \cdot \frac{W}{g m}$

$$
\text { BottomSpacerHR }:=\text { BottomSpacer } \cdot \rho_{S S}=\left[\begin{array}{ll}
0.708 & 0.708
\end{array}\right] \frac{B T U}{s \cdot i n^{3}}
$$




\section{Appendix C - Heat Transfer Coefficients}

Conductivity of the Helium-Argon mixtures are from the Thermophysical Properties of Matter Database, Gas Mixture: Monatomic Systems, Argon - Helium Mixtures, Ar - He.

https://cindasdata.com/Applications/TPMD/?action=+Show+Graph

$+\&$ subaction $=\&$ mgcode $=T G 41 \&$ pgcode $=\&$ mcode $=01600 \&$ mname $=\&$ pname $=\&$ pcode $=0101 \&$ indvar $=0676 \&$ prop_and_indvar $=0101 \% 3 A 0676 \&$ prop_range_min $=\&$ prop_range_max $=\&$ smcode $\%$ 3Alist $=01600 \&$ sdatacurves $\% 3$ Alist $=4300 \% 3 \mathrm{~A} 4$

Gas gaps at nominal and hot gap conditions were calculated in ECAR-3672. Gap conductance values for all gas mixtures at nominal gaps and $85 \mathrm{HeAr} 15$ for hot gaps were calculated and documented in ECAR-3672 and were not repeated here. The hot gap conductance for He40Ar60, $\mathrm{He} 25 \mathrm{Ar} 75$, and Ar100 are calculated below.

$$
\begin{aligned}
& T_{\text {HeAr }}:=\left[\begin{array}{l}
302.2 \\
793.2
\end{array}\right] K=\left[\begin{array}{r}
84 \\
968
\end{array}\right]{ }^{\circ} \mathrm{F} \\
& k_{40 H e 60 A r}:=\left[\begin{array}{l}
0.0451 \\
0.0957
\end{array}\right] \cdot \frac{W}{m \cdot K}=\left[\begin{array}{l}
0.00217 \\
0.00461
\end{array}\right] \frac{B T U}{\mathrm{hr} \cdot \mathrm{in} \cdot R} \\
& k_{25 H e 75 A r}:=\left[\begin{array}{l}
0.0326 \\
0.0693
\end{array}\right] \cdot \frac{W}{m \cdot K}=\left[\begin{array}{l}
0.00157 \\
0.00334
\end{array}\right] \frac{\mathrm{BTU}}{\mathrm{hr} \cdot \mathrm{in} \cdot R} \\
& k_{100 A r}:=\left[\begin{array}{l}
0.0182 \\
0.0383
\end{array}\right] \cdot \frac{W}{m \cdot K}=\left[\begin{array}{l}
0.00088 \\
0.00184
\end{array}\right] \frac{\mathrm{BTU}}{\mathrm{hr} \cdot \mathrm{in} \cdot R} \\
& d_{\text {hotgasgap }}:=\left[\begin{array}{l}
0.00100 \\
0.00135 \\
0.00285 \\
0.00935 \\
0.03835 \\
0.10835
\end{array}\right] \cdot \text { in }
\end{aligned}
$$


$40 \%$ Helium $60 \%$ Argon

$$
\begin{aligned}
& h_{40 \mathrm{He} 60 \mathrm{Ar} 0}:=\frac{k_{40 \mathrm{He} 60 \mathrm{Ar}}}{d_{\text {hotgasgap }_{0}}}=\left[\begin{array}{l}
0.00060 \\
0.00128
\end{array}\right] \frac{\mathrm{BTU}}{\mathrm{sec} \cdot \mathrm{in}^{2} \cdot R} \\
& h_{40 \mathrm{He} 60 \mathrm{Ar} 1}:=\frac{k_{40 \mathrm{He} 60 \mathrm{Ar}}}{d_{\text {hotgasgap }_{1}}}=\left[\begin{array}{l}
0.00045 \\
0.00095
\end{array}\right] \frac{\mathrm{BTU}}{\mathrm{sec} \cdot \mathrm{in}^{2} \cdot R} \\
& h_{40 \mathrm{He} 60 \mathrm{Ar} 2}:=\frac{k_{40 \mathrm{He} 60 \mathrm{Ar}}}{d_{\text {hotgasgap }_{2}}}=\left[\begin{array}{l}
0.00021 \\
0.00045
\end{array}\right] \frac{B T U}{\mathrm{sec} \cdot \mathrm{in}^{2} \cdot R} \\
& h_{40 \mathrm{He} 60 \mathrm{Ar} 3}:=\frac{k_{40 \mathrm{He} 6 \mathrm{Ar}}}{d_{\text {hotgasgap }_{3}}}=\left[\begin{array}{l}
0.000065 \\
0.000137
\end{array}\right] \frac{B T U}{\mathrm{sec} \cdot \mathrm{in}^{2} \cdot R} \\
& h_{40 \mathrm{He} 60 \mathrm{Ar} 4}:=\frac{k_{40 \mathrm{He}} 60 \mathrm{Ar}}{d_{\text {hotgasgap }_{4}}}=\left[\begin{array}{l}
0.000016 \\
0.000033
\end{array}\right] \frac{B T U}{\mathrm{sec} \cdot \mathrm{in}^{2} \cdot R} \\
& h_{40 \mathrm{He} 60 \mathrm{Ar} 5}:=\frac{k_{40 \mathrm{He} 60 \mathrm{Ar}}}{d_{\text {hotgasgap }_{5}}}=\left[\begin{array}{l}
0.000006 \\
0.000012
\end{array}\right] \frac{B T U}{\mathrm{sec} \cdot \mathrm{in}^{2} \cdot R}
\end{aligned}
$$

$25 \%$ Helium $75 \%$ Argon

$$
\begin{aligned}
& h_{25 H e 75 A r 0}:=\frac{k_{25 H e 75 A r}}{d_{\text {hotgasgap }_{0}}}=\left[\begin{array}{l}
0.00044 \\
0.00093
\end{array}\right] \frac{B T U}{\mathrm{sec} \cdot \mathrm{in}^{2} \cdot R} \\
& h_{25 H e 75 A r 1}:=\frac{k_{25 H e 75 A r}}{d_{\text {hotgasgap }_{1}}}=\left[\begin{array}{l}
0.00032 \\
0.00069
\end{array}\right] \frac{B T U}{\mathrm{sec} \cdot \text { in }^{2} \cdot R} \\
& h_{25 \mathrm{He}_{5 \mathrm{Ar} 2}}:=\frac{k_{25 \mathrm{He} 75 \mathrm{Ar}}}{d_{\text {hotgasgap }_{2}}}=\left[\begin{array}{l}
0.00015 \\
0.00033
\end{array}\right] \frac{\mathrm{BTU}}{\mathrm{sec} \cdot \mathrm{in}^{2} \cdot R} \\
& h_{25 H e 75 A r 3}:=\frac{k_{25 H e 75 A r}}{d_{\text {hotgasgap }_{3}}}=\left[\begin{array}{l}
0.000047 \\
0.000099
\end{array}\right] \frac{B T U}{\mathrm{sec} \cdot \text { in }^{2} \cdot R} \\
& h_{25 H e 75 A r 4}:=\frac{k_{25 H e 75 A r}}{d_{\text {hotgasgap }_{4}}}=\left[\begin{array}{l}
0.000011 \\
0.000024
\end{array}\right] \frac{B T U}{\mathrm{sec} \cdot i n^{2} \cdot R} \\
& h_{25 H e 75 \text { Ar } 5}:=\frac{k_{25 H e 75 A r}}{d_{\text {hotgasgap }_{5}}}=\left[\begin{array}{l}
0.000004 \\
0.000009
\end{array}\right] \frac{B T U}{\mathrm{sec} \cdot \text { in }^{2} \cdot R}
\end{aligned}
$$


$100 \%$ Argon

$$
\begin{aligned}
& h_{100 A r 0}:=\frac{k_{100 A r}}{d_{\text {hotgasgap }_{0}}}=\left[\begin{array}{l}
0.00024 \\
0.00051
\end{array}\right] \frac{B T U}{{\mathrm{sec} \cdot i n^{2} \cdot R}^{2}} \\
& h_{100 A r 1}:=\frac{k_{100 A r}}{d_{\text {hotgasgap }_{1}}}=\left[\begin{array}{l}
0.00018 \\
0.00038
\end{array}\right] \frac{B T U}{\mathrm{sec} \cdot \mathrm{in}^{2} \cdot R} \\
& h_{100 \mathrm{Ar} 2}:=\frac{k_{100 \mathrm{Ar}}}{d_{\text {hotgasgap }_{2}}}=\left[\begin{array}{l}
0.000085 \\
0.000180
\end{array}\right] \frac{\mathrm{BTU}}{\mathrm{sec} \cdot \mathrm{in}^{2} \cdot R} \\
& h_{100 \mathrm{Ar} 3}:=\frac{k_{100 \mathrm{Ar}}}{d_{\text {hotgasgap }_{3}}}=\left[\begin{array}{l}
0.000026 \\
0.000055
\end{array}\right] \frac{B T U}{\mathrm{sec} \cdot \mathrm{in}^{2} \cdot R} \\
& h_{100 \mathrm{Ar} 4}:=\frac{k_{100 \mathrm{Ar}}}{d_{\text {hotgasgap }_{4}}}=\left[\begin{array}{l}
0.000006 \\
0.000013
\end{array}\right] \frac{B T U}{\mathrm{sec} \cdot \mathrm{in}^{2} \cdot R} \\
& h_{100 A r 5}:=\frac{k_{100 A r}}{d_{\text {hotgasgap }_{5}}}=\left[\begin{array}{l}
0.0000022 \\
0.0000047
\end{array}\right] \frac{B T U}{\mathrm{sec} \cdot \mathrm{in}^{2} \cdot R}
\end{aligned}
$$




\begin{tabular}{|lrr|}
\hline TEM-10200-1, Rev. 11 & ENGINEERING CALCULATIONS AND ANALYSIS & ECAR-4907, Rev. 0 \\
$11 / 20 / 2019$ & Page D1 of D4 \\
& As-Run Thermal Analysis for the CSM-10584 Experiment & \\
\hline
\end{tabular}

\section{Appendix D - ABAQUS Validation}

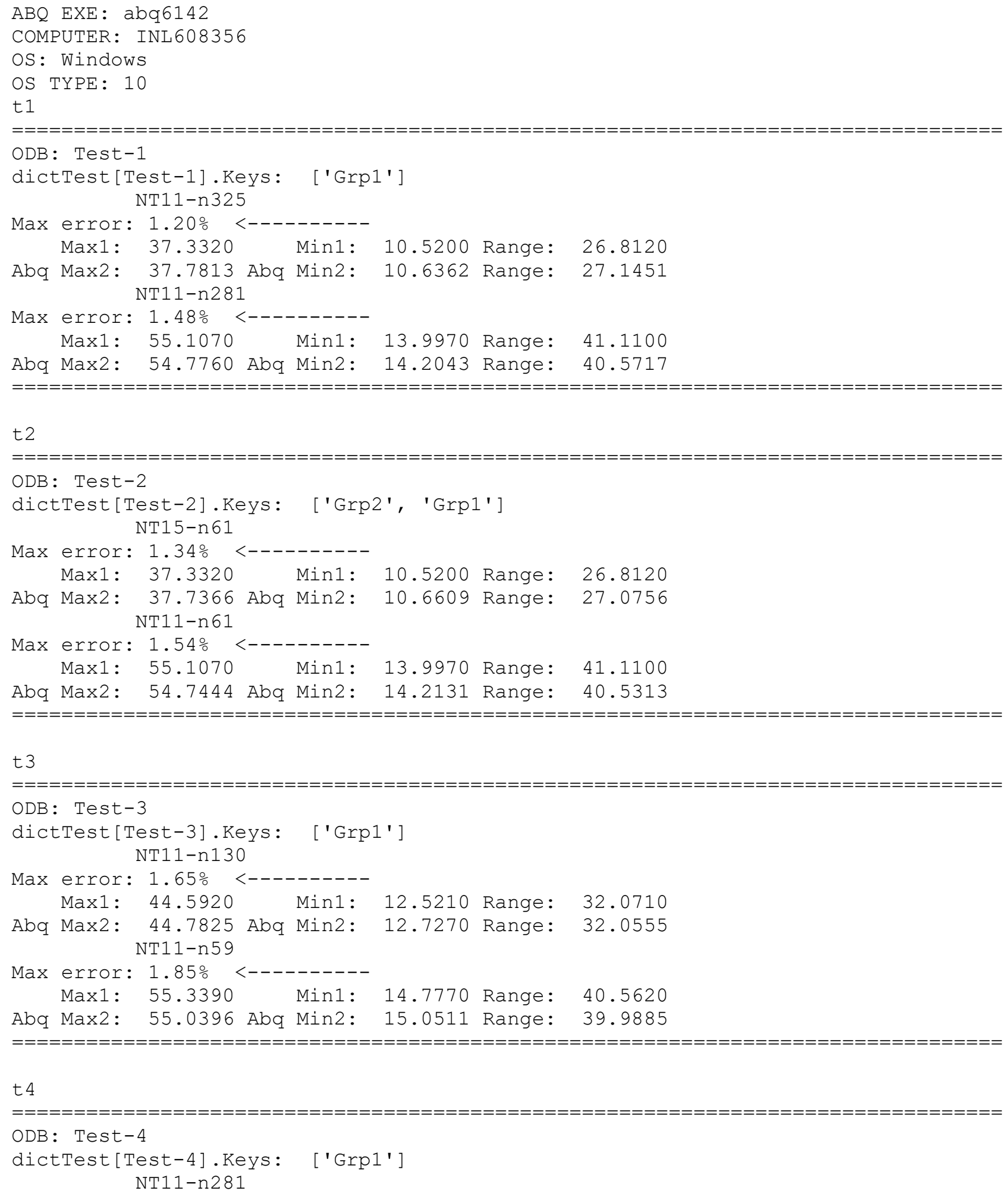




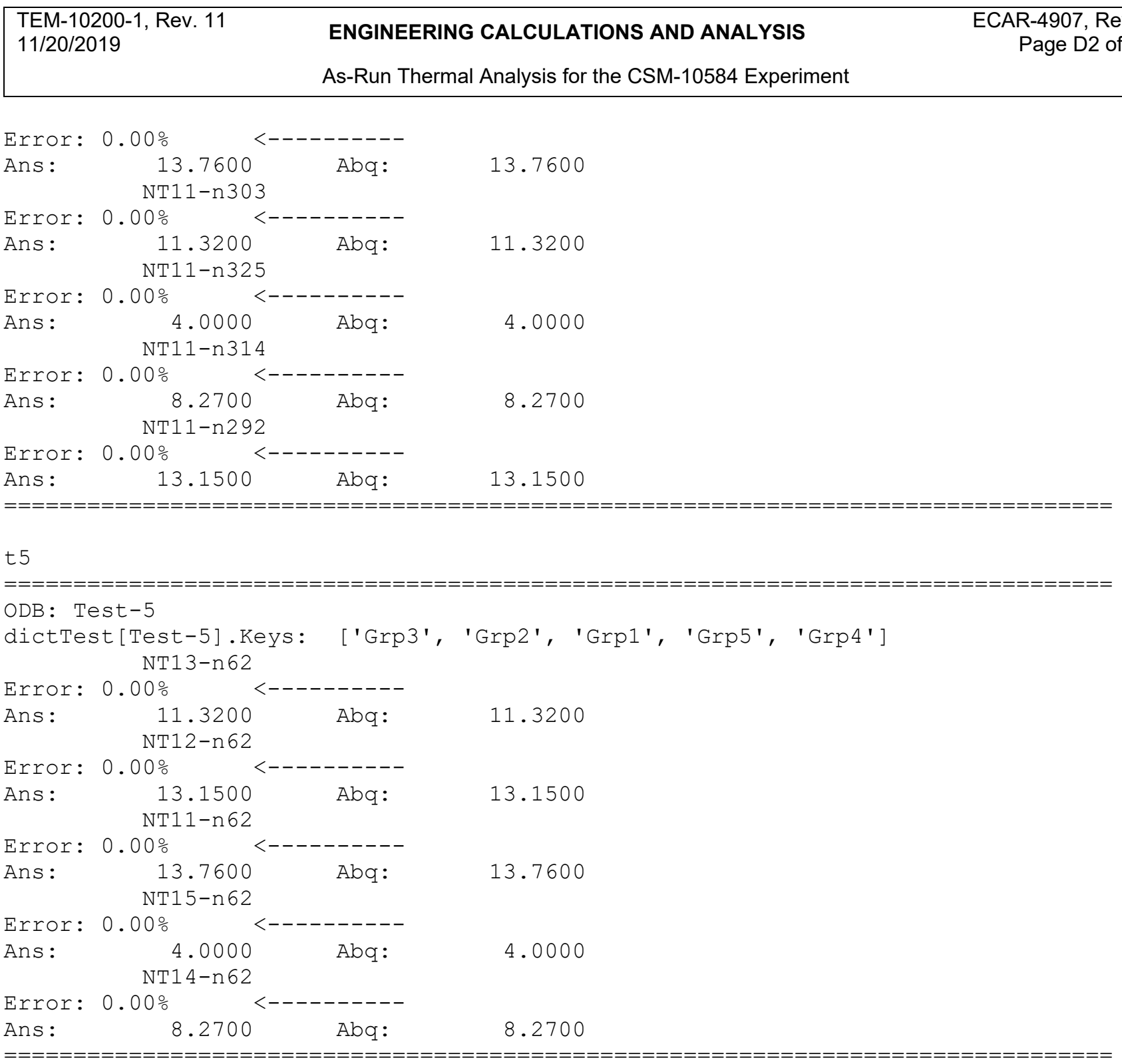

\section{t6}

$=\mathrm{C}=\mathrm{=}=\mathrm{=}=\mathrm{=}=\mathrm{=}=\mathrm{=}=\mathrm{=}=\mathrm{=}=\mathrm{=}=\mathrm{=}=\mathrm{=}=\mathrm{=}=\mathrm{=}=\mathrm{=}=\mathrm{=}=\mathrm{=}=\mathrm{=}=\mathrm{=}=\mathrm{=}=\mathrm{=}=\mathrm{=}=\mathrm{=}=\mathrm{=}=\mathrm{=}=\mathrm{=}=\mathrm{=}=\mathrm{=}=\mathrm{=}=\mathrm{=}$ ODB: Test-6

dictTest [Test-6].Keys: ['Grp1'] $\mathrm{NT} 11-\mathrm{n} 533$

Max error: $0.39 \%<----------$

Max1: 80.7640 Min1: 61.8970 Range: 18.8670

Abq Max2: 80.4914 Abq Min2: 61.7364 Range: 18.7551 NT11-n803

Max error: $0.38 \%$

Max1: 94.5930 Min1: 71.5310 Range: 23.0620

Abq Max2: 94.3007 Abq Min2: 71.2781 Range: 23.0226

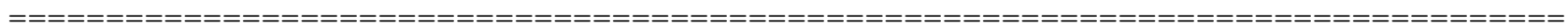

t7

$=\mathrm{e}=\mathrm{=}=\mathrm{=}=\mathrm{=}=\mathrm{=}=\mathrm{=}=\mathrm{=}=\mathrm{=}=\mathrm{=}=\mathrm{=}=\mathrm{=}=\mathrm{=}=\mathrm{=}=\mathrm{=}=\mathrm{=}=\mathrm{=}=\mathrm{=}=\mathrm{=}=\mathrm{=}=\mathrm{=}=\mathrm{=}=\mathrm{=}=\mathrm{=}=\mathrm{=}=\mathrm{=}=\mathrm{=}=\mathrm{=}=\mathrm{=}=\mathrm{=}$ ODB: Test-7

dictTest [Test-7].Keys: ['Grp1'] 


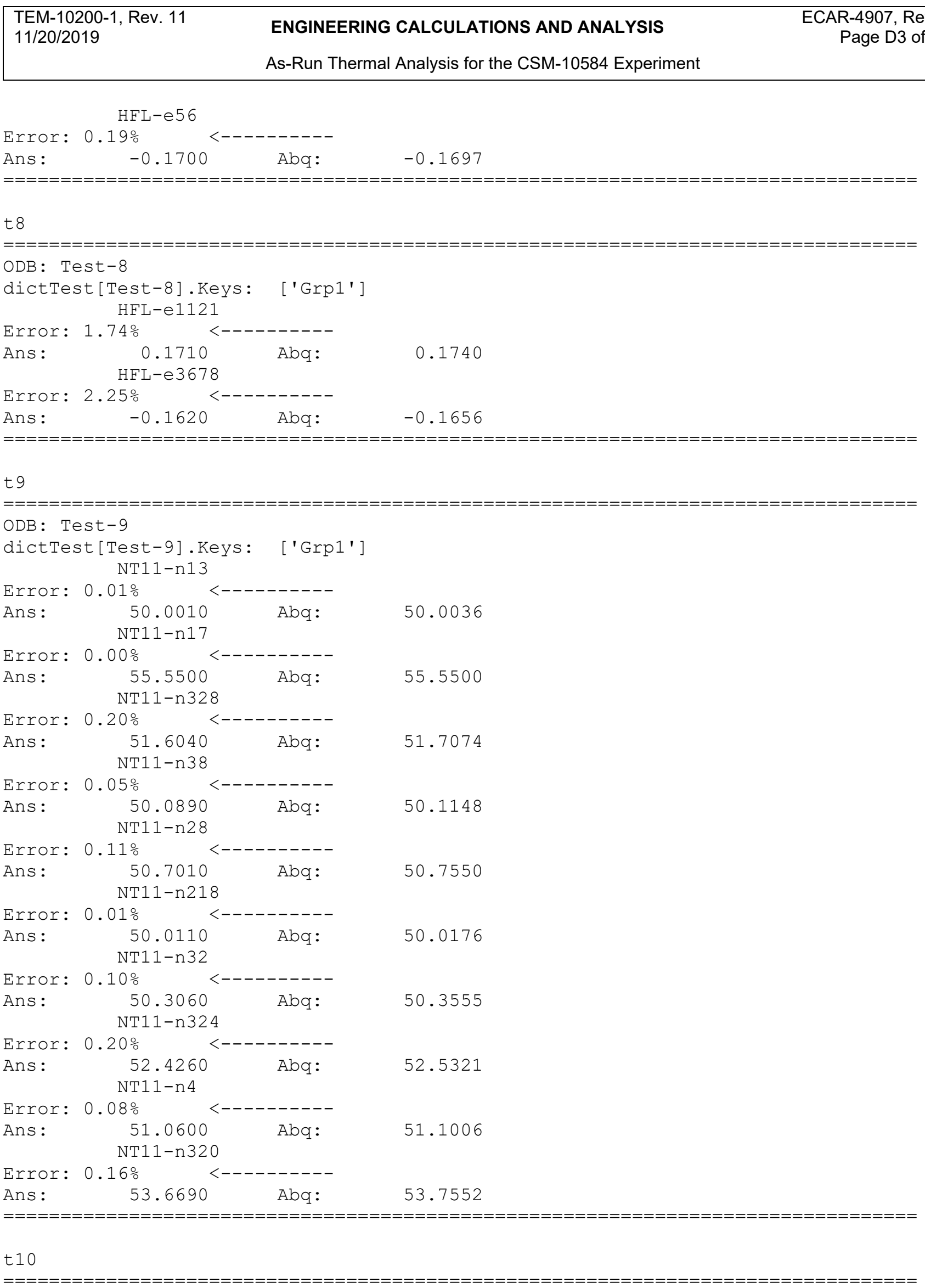




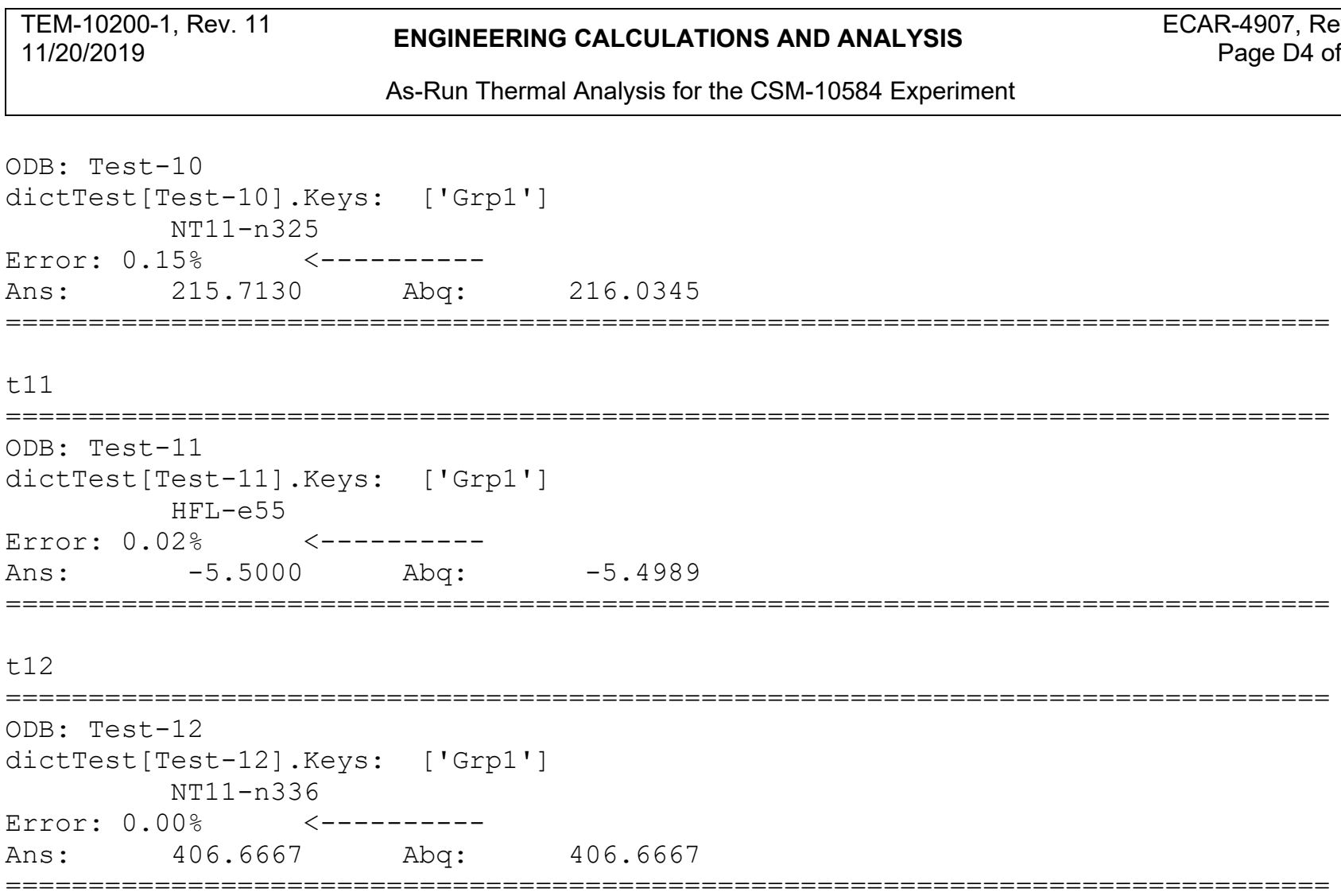


As-Run Thermal Analysis for the CSM-10584 Experiment

\section{Appendix E - Specimen Temperature Results}

Table E1 - Cycle 164A Specimen Temperatures at Nominal Power (22.5MW) and Gas Gap

\begin{tabular}{|c|c|c|c|c|c|c|c|}
\hline Capsule & Holder & Specimen Stack & Material & $\begin{array}{c}\text { Minimum } \\
\left({ }^{\circ} \mathrm{F}\right)\end{array}$ & $\begin{array}{c}\text { Minimum } \\
\left({ }^{\circ} \mathrm{C}\right)\end{array}$ & $\begin{array}{c}\text { Maximum } \\
\left({ }^{\circ} \mathrm{F}\right)\end{array}$ & $\begin{array}{c}\text { Maximum } \\
\left({ }^{\circ} \mathrm{C}\right)\end{array}$ \\
\hline \multirow{2}{*}{ A } & A-1 & Tensile & SS316 & 586 & 308 & 622 & 328 \\
\hline & A-2 & Tensile & Inconel & 678 & 359 & 737 & 392 \\
\hline \multirow{2}{*}{ B } & B-1 & Tensile & SS316 & 586 & 308 & 632 & 333 \\
\hline & B-2 & Tensile & Inconel & 655 & 346 & 727 & 386 \\
\hline \multirow{12}{*}{ C } & \multirow{5}{*}{$C-1$} & PIE TPP & SS316 & 583 & 306 & 633 & 334 \\
\hline & & PIE TEM 1 & SS316 & 528 & 276 & 537 & 281 \\
\hline & & PIE TEM 2 & SS316 & 528 & 276 & 538 & 281 \\
\hline & & PIE TEM 3 & SS316 & 527 & 275 & 536 & 280 \\
\hline & & PIE TEM 4 & SS316 & 527 & 275 & 536 & 280 \\
\hline & $\mathrm{C}-2$ & Tensile & SS316 & 547 & 286 & 632 & 333 \\
\hline & C-3 & Tensile & Inconel & 554 & 290 & 681 & 361 \\
\hline & \multirow{5}{*}{$\mathrm{C}-4$} & PIE TPP & Inconel & 609 & 321 & 686 & 363 \\
\hline & & PIE TEM 1 & Inconel & 548 & 287 & 565 & 296 \\
\hline & & PIE TEM 2 & Inconel & 548 & 287 & 565 & 296 \\
\hline & & PIE TEM 3 & Inconel & 547 & 286 & 563 & 295 \\
\hline & & PIE TEM 4 & Inconel & 548 & 287 & 564 & 296 \\
\hline \multirow{10}{*}{ D } & \multirow{5}{*}{ D-1 } & PIE TPP & SS316 & 594 & 312 & 628 & 331 \\
\hline & & PIE TEM 1 & SS316 & 521 & 272 & 525 & 274 \\
\hline & & PIE TEM 2 & SS316 & 521 & 272 & 526 & 274 \\
\hline & & PIE TEM 3 & SS316 & 521 & 272 & 525 & 274 \\
\hline & & PIE TEM 4 & SS316 & 520 & 271 & 525 & 274 \\
\hline & \multirow{5}{*}{ D-2 } & PIE TPP & Inconel & 578 & 303 & 624 & 329 \\
\hline & & PIE TEM 1 & Inconel & 510 & 266 & 517 & 269 \\
\hline & & PIE TEM 2 & Inconel & 511 & 266 & 517 & 269 \\
\hline & & PIE TEM 3 & Inconel & 509 & 265 & 516 & 269 \\
\hline & & PIE TEM 4 & Inconel & 509 & 265 & 516 & 269 \\
\hline \multirow{10}{*}{$E$} & \multirow{5}{*}{$E-1$} & PIE TPP & SS316 & 594 & 312 & 621 & 327 \\
\hline & & PIE TEM 1 & SS316 & 523 & 273 & 526 & 274 \\
\hline & & PIE TEM 2 & SS316 & 523 & 273 & 526 & 274 \\
\hline & & PIE TEM 3 & SS316 & 522 & 272 & 525 & 274 \\
\hline & & PIE TEM 4 & SS316 & 522 & 272 & 525 & 274 \\
\hline & \multirow{5}{*}{ E-2 } & PIE TPP & Inconel & 572 & 300 & 608 & 320 \\
\hline & & PIE TEM 1 & Inconel & 505 & 263 & 509 & 265 \\
\hline & & PIE TEM 2 & Inconel & 505 & 263 & 509 & 265 \\
\hline & & PIE TEM 3 & Inconel & 505 & 263 & 509 & 265 \\
\hline & & PIE TEM 4 & Inconel & 505 & 263 & 509 & 265 \\
\hline
\end{tabular}


As-Run Thermal Analysis for the CSM-10584 Experiment

Table E2 - Cycle 164B Specimen Temperatures at Nominal Power (22.6MW) and Gas Gap

\begin{tabular}{|c|c|c|c|c|c|c|c|}
\hline Capsule & Holder & Specimen Stack & Material & $\begin{array}{c}\text { Minimum } \\
\left({ }^{\circ} \mathrm{F}\right)\end{array}$ & $\begin{array}{c}\text { Minimum } \\
\left({ }^{\circ} \mathrm{C}\right)\end{array}$ & $\begin{array}{c}\text { Maximum } \\
\left({ }^{\circ} \mathrm{F}\right)\end{array}$ & $\begin{array}{c}\text { Maximum } \\
\left({ }^{\circ} \mathrm{C}\right)\end{array}$ \\
\hline \multirow{2}{*}{ A } & $A-1$ & Tensile & SS316 & -- & -- & -- & -- \\
\hline & $A-2$ & Tensile & Inconel & $\overline{---}$ & -- & $\overline{---}$ & $\overline{---}$ \\
\hline \multirow{2}{*}{ B } & B-1 & Tensile & SS316 & 590 & 310 & 636 & 336 \\
\hline & B-2 & Tensile & Inconel & 657 & 347 & 728 & 387 \\
\hline \multirow{12}{*}{ C } & \multirow{5}{*}{$\mathrm{C}-1$} & PIE TPP & SS316 & 583 & 306 & 634 & 334 \\
\hline & & PIE TEM 1 & SS316 & 528 & 276 & 538 & 281 \\
\hline & & PIE TEM 2 & SS316 & 528 & 276 & 538 & 281 \\
\hline & & PIE TEM 3 & SS316 & 527 & 275 & 537 & 281 \\
\hline & & PIE TEM 4 & SS316 & 527 & 275 & 537 & 281 \\
\hline & $\mathrm{C}-2$ & Tensile & SS316 & 549 & 287 & 634 & 334 \\
\hline & $\mathrm{C}-3$ & Tensile & Inconel & 555 & 291 & 682 & 361 \\
\hline & \multirow{5}{*}{ C-4 } & PIE TPP & Inconel & 612 & 322 & 689 & 365 \\
\hline & & PIE TEM 1 & Inconel & 549 & 287 & 567 & 297 \\
\hline & & PIE TEM 2 & Inconel & 550 & 288 & 567 & 297 \\
\hline & & PIE TEM 3 & Inconel & 548 & 287 & 565 & 296 \\
\hline & & PIE TEM 4 & Inconel & 549 & 287 & 566 & 297 \\
\hline \multirow{10}{*}{ D } & \multirow{5}{*}{ D-1 } & PIE TPP & SS316 & 594 & 312 & 628 & 331 \\
\hline & & PIE TEM 1 & SS316 & 522 & 272 & 526 & 274 \\
\hline & & PIE TEM 2 & SS316 & 522 & 272 & 526 & 274 \\
\hline & & PIE TEM 3 & SS316 & 521 & 272 & 526 & 274 \\
\hline & & PIE TEM 4 & SS316 & 521 & 272 & 526 & 274 \\
\hline & \multirow{5}{*}{ D-2 } & PIE TPP & Inconel & 580 & 304 & 626 & 330 \\
\hline & & PIE TEM 1 & Inconel & 512 & 267 & 518 & 270 \\
\hline & & PIE TEM 2 & Inconel & 512 & 267 & 519 & 271 \\
\hline & & PIE TEM 3 & Inconel & 511 & 266 & 517 & 269 \\
\hline & & PIE TEM 4 & Inconel & 511 & 266 & 517 & 269 \\
\hline \multirow{10}{*}{ E } & \multirow{5}{*}{$\mathrm{E}-1$} & PIE TPP & SS316 & -- & --- & --- & --- \\
\hline & & PIE TEM 1 & SS316 & --- & -- & -- & -- \\
\hline & & PIE TEM 2 & SS316 & --- & --- & --- & --- \\
\hline & & PIE TEM 3 & SS316 & -- & -- & --- & -- \\
\hline & & PIE TEM 4 & SS316 & -- & -- & --- & -- \\
\hline & \multirow{5}{*}{ E-2 } & PIE TPP & Inconel & -- & -- & -- & --- \\
\hline & & PIE TEM 1 & Inconel & --- & -- & --- & --- \\
\hline & & PIE TEM 2 & Inconel & --- & -- & -- & -- \\
\hline & & PIE TEM 3 & Inconel & --- & -- & -- & --- \\
\hline & & PIE TEM 4 & Inconel & --- & --- & -- & -- \\
\hline
\end{tabular}




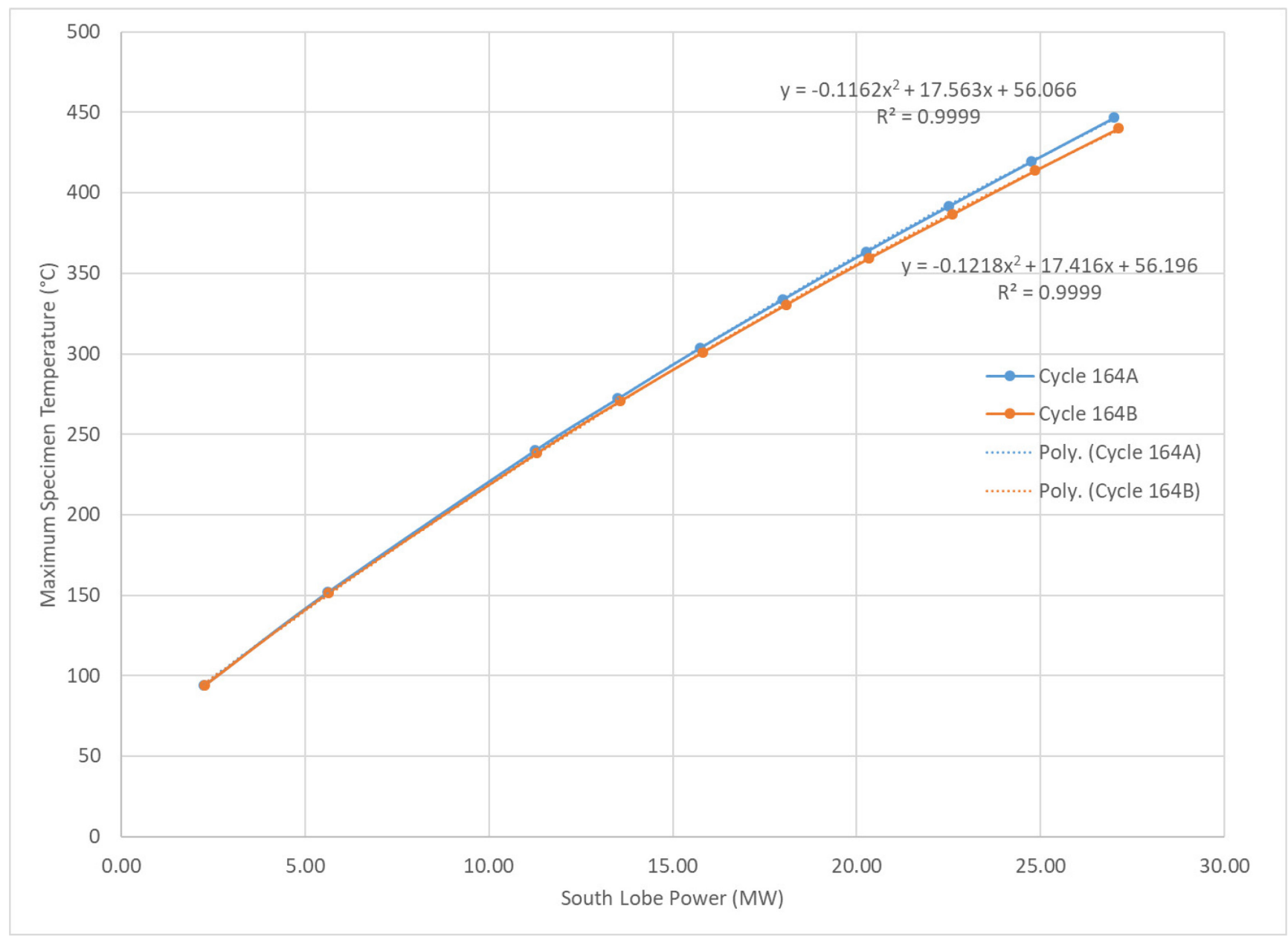

Figure E1 - Maximum Specimen Temperature at Various Power Levels for Each Cycle 
As-Run Thermal Analysis for the CSM-10584 Experiment

Table E3 - Cycle 164A Specimen Temperatures at Nominal Power (22.5MW) and Hot Gas Gap

\begin{tabular}{|c|c|c|c|c|c|c|c|}
\hline Capsule & Holder & Specimen Stack & Material & $\begin{array}{c}\text { Minimum } \\
\left({ }^{\circ} \mathrm{F}\right)\end{array}$ & $\begin{array}{c}\text { Minimum } \\
\left({ }^{\circ} \mathrm{C}\right)\end{array}$ & $\begin{array}{c}\text { Maximum } \\
\left({ }^{\circ} \mathrm{F}\right)\end{array}$ & $\begin{array}{c}\text { Maximum } \\
\left({ }^{\circ} \mathrm{C}\right)\end{array}$ \\
\hline \multirow{2}{*}{ A } & $A-1$ & Tensile & SS316 & 567 & 297 & 604 & 318 \\
\hline & $A-2$ & Tensile & Inconel & 660 & 349 & 721 & 383 \\
\hline \multirow{2}{*}{ B } & B-1 & Tensile & SS316 & 530 & 277 & 578 & 303 \\
\hline & B-2 & Tensile & Inconel & 600 & 316 & 674 & 357 \\
\hline \multirow{12}{*}{ C } & \multirow{5}{*}{$\mathrm{C}-1$} & PIE TPP & SS316 & 554 & 290 & 605 & 318 \\
\hline & & PIE TEM 1 & SS316 & 496 & 258 & 506 & 263 \\
\hline & & PIE TEM 2 & SS316 & 497 & 258 & 507 & 264 \\
\hline & & PIE TEM 3 & SS316 & 496 & 258 & 505 & 263 \\
\hline & & PIE TEM 4 & SS316 & 496 & 258 & 505 & 263 \\
\hline & C-2 & Tensile & SS316 & 514 & 268 & 602 & 317 \\
\hline & C-3 & Tensile & Inconel & 521 & 272 & 650 & 343 \\
\hline & \multirow{5}{*}{ C-4 } & PIE TPP & Inconel & 579 & 304 & 657 & 347 \\
\hline & & PIE TEM 1 & Inconel & 515 & 268 & 532 & 278 \\
\hline & & PIE TEM 2 & Inconel & 515 & 268 & 532 & 278 \\
\hline & & PIE TEM 3 & Inconel & 514 & 268 & 531 & 277 \\
\hline & & PIE TEM 4 & Inconel & 515 & 268 & 532 & 278 \\
\hline \multirow{10}{*}{ D } & \multirow{5}{*}{ D-1 } & TPP TEM & SS316 & 565 & 296 & 600 & 316 \\
\hline & & PIE TEM 1 & SS316 & 491 & 255 & 495 & 257 \\
\hline & & PIE TEM 2 & SS316 & 491 & 255 & 496 & 258 \\
\hline & & PIE TEM 3 & SS316 & 490 & 254 & 495 & 257 \\
\hline & & PIE TEM 4 & SS316 & 490 & 254 & 495 & 257 \\
\hline & \multirow{5}{*}{ D-2 } & PIE TPP & Inconel & 550 & 288 & 596 & 313 \\
\hline & & PIE TEM 1 & Inconel & 480 & 249 & 487 & 253 \\
\hline & & PIE TEM 2 & Inconel & 481 & 249 & 487 & 253 \\
\hline & & PIE TEM 3 & Inconel & 479 & 248 & 486 & 252 \\
\hline & & PIE TEM 4 & Inconel & 479 & 248 & 486 & 252 \\
\hline \multirow{10}{*}{$E$} & \multirow{5}{*}{$E-1$} & PIE TPP & SS316 & 550 & 288 & 579 & 304 \\
\hline & & PIE TEM 1 & SS316 & 476 & 247 & 479 & 248 \\
\hline & & PIE TEM 2 & SS316 & 476 & 247 & 479 & 248 \\
\hline & & PIE TEM 3 & SS316 & 475 & 246 & 478 & 248 \\
\hline & & PIE TEM 4 & SS316 & 475 & 246 & 478 & 248 \\
\hline & \multirow{5}{*}{$E-2$} & PIE TPP & Inconel & 528 & 276 & 565 & 296 \\
\hline & & PIE TEM 1 & Inconel & 458 & 237 & 462 & 239 \\
\hline & & PIE TEM 2 & Inconel & 458 & 237 & 462 & 239 \\
\hline & & PIE TEM 3 & Inconel & 458 & 237 & 462 & 239 \\
\hline & & PIE TEM 4 & Inconel & 458 & 237 & 462 & 239 \\
\hline
\end{tabular}


As-Run Thermal Analysis for the CSM-10584 Experiment

Table E4 - Cycle 164B Specimen Temperatures at Nominal Power (22.6MW) and Hot Gas Gap

\begin{tabular}{|c|c|c|c|c|c|c|c|}
\hline Capsule & Holder & Specimen Stack & Material & $\begin{array}{c}\text { Minimum } \\
\left({ }^{\circ} \mathrm{F}\right)\end{array}$ & $\begin{array}{c}\text { Minimum } \\
\left({ }^{\circ} \mathrm{C}\right)\end{array}$ & $\begin{array}{c}\text { Maximum } \\
\left({ }^{\circ} \mathrm{F}\right)\end{array}$ & $\begin{array}{c}\text { Maximum } \\
\left({ }^{\circ} \mathrm{C}\right)\end{array}$ \\
\hline \multirow{2}{*}{ A } & $A-1$ & Tensile & SS316 & -- & -- & -- & -- \\
\hline & A-2 & Tensile & Inconel & -- & -- & -- & -- \\
\hline \multirow{2}{*}{ B } & $\mathrm{B}-1$ & Tensile & SS316 & 534 & 279 & 582 & 306 \\
\hline & B-2 & Tensile & Inconel & 601 & 316 & 675 & 357 \\
\hline \multirow{12}{*}{ C } & \multirow{5}{*}{ C-1 } & PIE TPP & SS316 & 554 & 290 & 606 & 319 \\
\hline & & PIE TEM 1 & SS316 & 497 & 258 & 507 & 264 \\
\hline & & PIE TEM 2 & SS316 & 497 & 258 & 507 & 264 \\
\hline & & PIE TEM 3 & SS316 & 496 & 258 & 506 & 263 \\
\hline & & PIE TEM 4 & SS316 & 496 & 258 & 506 & 263 \\
\hline & $\mathrm{C}-2$ & Tensile & SS316 & 515 & 268 & 604 & 318 \\
\hline & C-3 & Tensile & Inconel & 521 & 272 & 651 & 344 \\
\hline & \multirow{5}{*}{ C-4 } & PIE TPP & Inconel & 581 & 305 & 660 & 349 \\
\hline & & PIE TEM 1 & Inconel & 517 & 269 & 534 & 279 \\
\hline & & PIE TEM 2 & Inconel & 517 & 269 & 534 & 279 \\
\hline & & PIE TEM 3 & Inconel & 516 & 269 & 533 & 278 \\
\hline & & PIE TEM 4 & Inconel & 516 & 269 & 534 & 279 \\
\hline \multirow{10}{*}{ D } & \multirow{5}{*}{ D-1 } & PIE TPP & SS316 & 566 & 297 & 601 & 316 \\
\hline & & PIE TEM 1 & SS316 & 492 & 256 & 496 & 258 \\
\hline & & PIE TEM 2 & SS316 & 492 & 256 & 496 & 258 \\
\hline & & PIE TEM 3 & SS316 & 491 & 255 & 495 & 257 \\
\hline & & PIE TEM 4 & SS316 & 491 & 255 & 496 & 258 \\
\hline & \multirow{5}{*}{ D-2 } & PIE TPP & Inconel & 551 & 288 & 598 & 314 \\
\hline & & PIE TEM 1 & Inconel & 481 & 249 & 488 & 253 \\
\hline & & PIE TEM 2 & Inconel & 482 & 250 & 489 & 254 \\
\hline & & PIE TEM 3 & Inconel & 480 & 249 & 487 & 253 \\
\hline & & PIE TEM 4 & Inconel & 481 & 249 & 487 & 253 \\
\hline \multirow{10}{*}{$E$} & \multirow{5}{*}{$E-1$} & PIE TPP & SS316 & --- & -- & --- & --- \\
\hline & & PIE TEM 1 & SS316 & -- & -- & --- & -- \\
\hline & & PIE TEM 2 & SS316 & --- & -- & --- & -- \\
\hline & & PIE TEM 3 & SS316 & -- & -- & --- & -- \\
\hline & & PIE TEM 4 & SS316 & --- & -- & --- & --- \\
\hline & \multirow{5}{*}{$E-2$} & PIE TPP & Inconel & --- & -- & --- & --- \\
\hline & & PIE TEM 1 & Inconel & --- & --- & $\begin{array}{c}-- \\
--\end{array}$ & --- \\
\hline & & PIE TEM 2 & Inconel & --- & --- & --- & --- \\
\hline & & PIE TEM 3 & Inconel & -- & --- & --- & --- \\
\hline & & PIE TEM 4 & Inconel & -- & -- & -- & -- \\
\hline
\end{tabular}




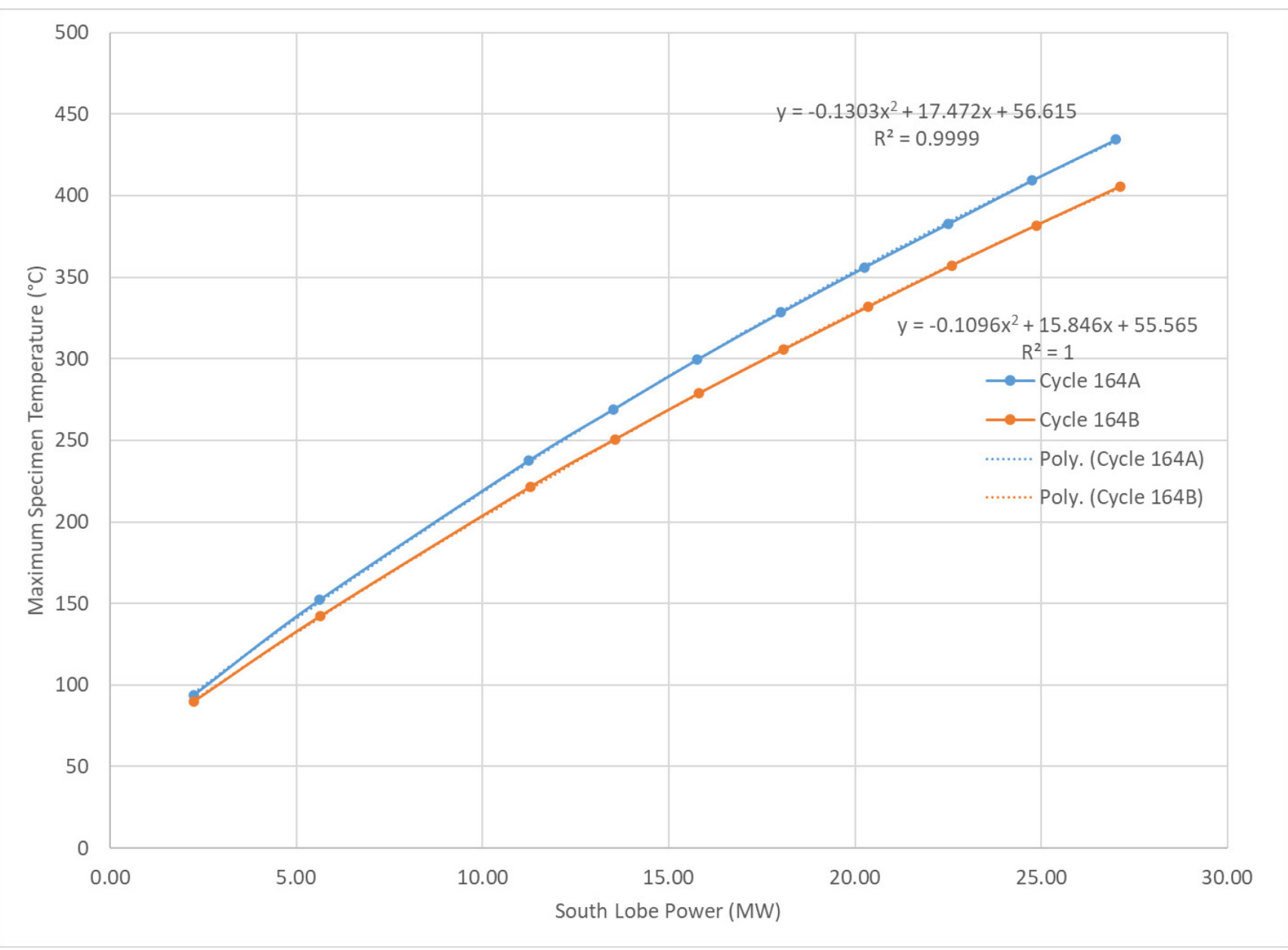

Figure E2 - Maximum Specimen Temperature at Various Power Levels for Each Cycle 


\begin{tabular}{|lrr|}
\hline TEM-10200-1, Rev. 11 & ENGINEERING CALCULATIONS AND ANALYSIS & ECAR-4907, Rev. 0 \\
$11 / 20 / 2019$ & As-Run Thermal Analysis for the CSM-10584 Experiment & Page E7 of E7
\end{tabular}

Table E5 - Specimen Stacks and Corresponding Specimen Numbers

\begin{tabular}{|c|c|c|c|c|}
\hline Capsule & Holder & $\begin{array}{c}\text { Specimen } \\
\text { Stack }\end{array}$ & Material & Specimen Numbers \\
\hline \multirow{2}{*}{ A } & A-1 & Tensile & SS316 & $1,2,3,4,145,146,147,148,161,162,163,164,217,218,219,220$ \\
\hline & A-2 & Tensile & Inconel & $13,14,15,16,73,74,75,76,89,90,91,92,229,230,231,232$ \\
\hline \multirow{2}{*}{ B } & $\mathrm{B}-1$ & Tensile & SS316 & $5,6,7,8,153,154,155,156,157,158,159,160,221,222,223,224$ \\
\hline & B-2 & Tensile & Inconel & $17,18,19,20,81,82,83,84,85,86,87,88,233,234,235,236$ \\
\hline \multirow{12}{*}{ C } & \multirow{5}{*}{ C-1 } & PIE TPP & SS316 & $25,26,27,28,177,178,179,180,181,182,183,184,241,242,243,244$ \\
\hline & & PIE TEM 1 & SS316 & $49,50,51,52$ \\
\hline & & PIE TEM 2 & SS316 & $289,291,206,208$ \\
\hline & & PIE TEM 3 & SS316 & $201,202,203,204$ \\
\hline & & PIE TEM 4 & SS316 & $265,266,267,268$ \\
\hline & $\mathrm{C}-2$ & Tensile & SS316 & $9,10,11,12,149,150,151,152,165,166,167,168,225,226,227,228$ \\
\hline & C-3 & Tensile & Inconel & $21,22,23,24,77,78,79,80,93,94,95,96,237,238,239,240$ \\
\hline & \multirow{5}{*}{ C-4 } & PIE TPP & Inconel & $37,38,39,40,97,98,99,100,113,114,115,116,253,254,255,256$ \\
\hline & & PIE TEM 1 & Inconel & $61,62,63,64$ \\
\hline & & PIE TEM 2 & Inconel & $121,122,123,124$ \\
\hline & & PIE TEM 3 & Inconel & $137,138,139,140$ \\
\hline & & PIE TEM 4 & Inconel & $281,282,283,284$ \\
\hline \multirow{10}{*}{ D } & \multirow{5}{*}{ D-1 } & PIE TPP & SS316 & $29,30,31,32,169,170,171,172,185,186,187,188,245,246,247,248$ \\
\hline & & PIE TEM 1 & SS316 & $53,54,55,56$ \\
\hline & & PIE TEM 2 & SS316 & $193,194,195,196$ \\
\hline & & PIE TEM 3 & SS316 & $209,210,211,212$ \\
\hline & & PIE TEM 4 & SS316 & $269,270,271,272$ \\
\hline & \multirow{5}{*}{ D-2 } & PIE TPP & Inconel & $41,42,43,44,101,102,103,104,117,118,119,120,257,258,259,260$ \\
\hline & & PIE TEM 1 & Inconel & $65,66,67,68$ \\
\hline & & PIE TEM 2 & Inconel & $125,126,127,128$ \\
\hline & & PIE TEM 3 & Inconel & $141,142,143,144$ \\
\hline & & PIE TEM 4 & Inconel & $277,278,279,280$ \\
\hline \multirow{10}{*}{$\mathbf{E}$} & \multirow{5}{*}{$\mathrm{E}-1$} & PIE TPP & SS316 & $33,34,35,36,173,174,175,176,189,190,191,192,249,250,251,252$ \\
\hline & & PIE TEM 1 & SS316 & $57,58,59,60$ \\
\hline & & PIE TEM 2 & SS316 & $197,198,199,200$ \\
\hline & & PIE TEM 3 & SS316 & $213,214,215,216$ \\
\hline & & PIE TEM 4 & SS316 & $273,274,275,276$ \\
\hline & \multirow{5}{*}{$\mathrm{E}-2$} & PIE TPP & Inconel & $45,46,47,48,105,106,107,108,109,110,111,112,261,262,263,264$ \\
\hline & & PIE TEM 1 & Inconel & $69,70,71,72$ \\
\hline & & PIE TEM 2 & Inconel & $129,130,131,132$ \\
\hline & & PIE TEM 3 & Inconel & $133,134,135,136$ \\
\hline & & PIE TEM 4 & Inconel & $285,286,287,288$ \\
\hline
\end{tabular}




\begin{tabular}{|lrr|}
\hline $\begin{array}{l}\text { TEM-10200-1, Rev. } 11 \\
11 / 20 / 2019\end{array}$ & ENGINEERING CALCULATIONS AND ANALYSIS & ECAR-4907, Rev. 0 \\
& Page F1 of F1 \\
\hline
\end{tabular}

\section{Appendix F - Analysis Request}

Stacey M. Wilson

From:

Sent:

To:

Cc:

Subject:

Follow Up Flag:

Flag Status:
Donna P. Guillen

Monday, December 16, 2019 4:32 PM

Katie A. Anderson; Stacey M. Wilson

Misti A. Lillo

RE: CSM Thermal As-Run

Follow up

Completed

Thanks, Stacey. The PI has requested the as-run temperatures by specimen, as well as a thermal history for the specimens. It will be good enough if you can estimate the thermal history without the need for a detailed neutronics analysis for the history.

Katie - The thermal history might take a bit more hours.

From: Katie A. Anderson <katie.anderson@inl.gov>

Sent: Monday, December 16, 2019 1:47 PM

To: Stacey M. Wilson <stacey.wilson@inl.gov>

Cc: Misti A. Lillo<misti.lillo@inl.gov>; Donna P. Guillen <donna.guillen@inl.gov>

Subject: RE: CSM Thermal As-Run

Hi Stacey,

That sounds great! I will plan on 80 hours to include your time as well as a tech checker. There should be two cycles of as-run results: cycle 164A and 164B for the B-5 position. You can use charge number $1027406 \mathrm{AO}$ and you can start any time you want. I don't think we have a specific "need by" date, just at your earliest convenience. Let me know if you have any other questions.

Thanks!

Katie

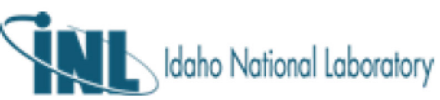

KATIE ANDERSON | Experiment Manager

Irradiation Testing

Idaho National Laboratory | 2525 North Fremont Ave. | Idaho Falls, ID 83415 | Mail Stop 3890

Phone: 208-526-0049 | Cell: 208-520-1197

Katie.anderson@inl.gov 